University of Nebraska - Lincoln

DigitalCommons@University of Nebraska - Lincoln

Comparative Lipid Production by Oleaginous Yeasts in Hydrolyzates of Lignocellulosic Biomass and Process Strategy for High Titers

\author{
Patricia J. Slininger \\ USDA-ARS, pat.slininger@ars.usda.gov \\ Bruce S. Dien \\ USDA-ARS, Bruce.Dien@ars.usda.gov \\ Cletus P. Kurtzman \\ USDA-ARS \\ Bryan R. Moser \\ USDA-ARS, Bryan.Moser@ars.usda.gov \\ Erica L. Bakota \\ USDA-ARS
}

See next page for additional authors

Follow this and additional works at: https://digitalcommons.unl.edu/usdaarsfacpub

Slininger, Patricia J.; Dien, Bruce S.; Kurtzman, Cletus P.; Moser, Bryan R.; Bakota, Erica L.; Thompson, Stephanie R.; O'Bryan, Patrick J.; Cotta, Michael A.; Balan, Venkatesh; Jin, Mingjie; da Costa Sousa, Leonardo; and Dale, Bruce E., "Comparative Lipid Production by Oleaginous Yeasts in Hydrolyzates of Lignocellulosic Biomass and Process Strategy for High Titers" (2016). Publications from USDA-ARS / UNL Faculty. 1558.

https://digitalcommons.unl.edu/usdaarsfacpub/1558

This Article is brought to you for free and open access by the U.S. Department of Agriculture: Agricultural Research Service, Lincoln, Nebraska at DigitalCommons@University of Nebraska - Lincoln. It has been accepted for inclusion in Publications from USDA-ARS / UNL Faculty by an authorized administrator of DigitalCommons@University of Nebraska - Lincoln. 


\section{Authors}

Patricia J. Slininger, Bruce S. Dien, Cletus P. Kurtzman, Bryan R. Moser, Erica L. Bakota, Stephanie R. Thompson, Patrick J. O'Bryan, Michael A. Cotta, Venkatesh Balan, Mingjie Jin, Leonardo da Costa Sousa, and Bruce E. Dale 


\title{
Comparative Lipid Production by Oleaginous Yeasts in Hydrolyzates of Lignocellulosic Biomass and Process Strategy for High Titers
}

\author{
Patricia J. Slininger, ${ }^{1}$ Bruce S. Dien, ${ }^{1}$ Cletus P. Kurtzman, ${ }^{1}$ Bryan R. Moser, ${ }^{1}$ \\ Erica L. Bakota, ${ }^{1}$ Stephanie R. Thompson, ${ }^{1}$ Patricia J. O'Bryan, ${ }^{1}$ Michael A. Cotta, ${ }^{1}$ \\ Venkatesh Balan, ${ }^{2}$ Mingjie Jin, ${ }^{2}$ Leonardo da Costa Sousa, ${ }^{2}$ Bruce E. Dale ${ }^{2}$ \\ ${ }^{l}$ National Center for Agricultural Utilization Research, USDA-ARS, Peoria, Illinois 61604; \\ telephone: 1-309-681-6286; fax: 1-309-681-6427; e-mail: Pat.Slininger@ars.usda.gov \\ ${ }^{2}$ DOE Great Lakes Bioenergy Research Center, Michigan State University, Lansing, \\ Michigan
}

\begin{abstract}
Oleaginous yeasts can convert sugars to lipids with fatty acid profiles similar to those of vegetable oils, making them attractive for production of biodiesel. Lignocellulosic biomass is an attractive source of sugars for yeast lipid production because it is abundant, potentially low cost, and renewable. However, lignocellulosic hydrolyzates are laden with byproducts which inhibit microbial growth and metabolism. With the goal of identifying oleaginous yeast strains able to convert plant biomass to lipids, we screened 32 strains from the ARS Culture Collection, Peoria, IL to identify four robust strains able to produce high lipid concentrations from both acid and base-pretreated biomass. The screening was arranged in two tiers using undetoxified enzyme hydrolyzates of ammonia fiber expansion (AFEX)-pretreated cornstover as the primary screening medium and acid-pretreated switch grass as the secondary screening medium applied to strains passing the primary screen. Hydrolyzates were prepared at $\sim 18-20 \%$ solids loading to provide $\sim 110 \mathrm{~g} / \mathrm{L}$ sugars at $\sim 56: 39: 5$ mass ratio glucose: xylose:arabinose. A two stage process boosting the molar $\mathrm{C}: \mathrm{N}$ ratio from 60 to well above 400 in undetoxified switchgrass hydrolyzate was optimized with respect to nitrogen source, C:N, and carbon loading. Using this process three strains were able to consume acetic acid and nearly all available sugars to accumulate $50-65 \%$ of cell biomass as lipid (w/w), to produce $25-30 \mathrm{~g} / \mathrm{L}$ lipid at $0.12-$ $0.22 \mathrm{~g} / \mathrm{L} / \mathrm{h}$ and $0.13-0.15 \mathrm{~g} / \mathrm{g}$ or $39-45 \%$ of the theoretical yield at $\mathrm{pH} 6$ and 7, a performance unprecedented in lignocellulosic hydrolyzates. Three of the top strains have not previously been reported for the bioconversion of lignocellulose to lipids. The successful identification and development of top-performing lipidproducing yeast in lignocellulose hydrolyzates is expected to advance the economic feasibility of high quality biodiesel and jet fuels from renewable biomass, expanding the market potential for
\end{abstract}

Disclaimer: The mention of trade names or commercial products in this article is solely for the purpose of providing specific information and does not imply recommendation or endorsement by the U.S. Department of Agriculture. USDA is an equal opportunity provider and employer.

Correspondence to: P.J. Slininger

Received 27 July 2015; Revision received 9 November 2015; Accepted 28 December 2015

Accepted manuscript online xx Month 2015;

Article first published online in Wiley Online Library

(wileyonlinelibrary.com).

DOI 10.1002/bit.25928 lignocellulose-derived fuels beyond ethanol for automobiles to the entire U.S. transportation market. Biotechnol. Bioeng. 2016; 9999: XX-XX. (c) 2016 Wiley Periodicals, Inc.

Biotechnol. Bioeng. 2016;9999: 1-15.

(C) 2016 Wiley Periodicals, Inc.

KEYWORDS: triacylglycerol; AFEX-pretreated corn stover; dilute acid-pretreated switchgrass; biodiesel; renewable energy

\section{Introduction}

It is expected that single cell oils (SCO) produced in the form of triacylglyerols (TAG) from agricultural residues and bioenergy crops can be a sustainable and significant source of biodiesel fuel. We estimated that oleaginous yeasts have the capability of producing $\sim 48$ and 190 gal oil per acre from corn stover and switchgrass, respectively. As a frame of reference, $\sim 68$ gallons of oil per acre are produced from processing soybeans. Based on conservative yields of switchgrass and process lipids, about 418 million dry U.S. tons biomass could be harvested each year and converted to at least 9.8 billion gallons of biodiesel/year. The latter estimate assumes 52.25 million acres, 8 tons biomass harvested/ acre, $50 \%$ recoverable monosaccharides, $0.2 \mathrm{~g}$ oil/g sugar yield, $90 \%$ lipid recovery, $7.68 \mathrm{lb} /$ gal oil density (Bates et al., 2008; Dien et al., 2006, 2013; Dugar and Stephanopoulos, 2011; Ratledge and Cohen, 2008). This would represent greater than $20 \%$ replacement of current annual U.S. diesel consumption with biodiesel from switchgrass alone, a figure which accounts for the energy content of biodiesel per volume as only $93 \%$ of diesel. Using all of the estimated 1.3 billion tons of biomass available for conversion to biofuel (U.S. Department of Energy, 2011), over 62\% of diesel could be replaced by yeast-based biodiesel fuel. This is significant although in actuality biomass will likely be converted to a variety of products. During 2014 the annual average domestic biodiesel production was only $\sim 1.1$ billion, or $2 \%$ of the 50 billion gallon U.S. diesel consumption (www.eia.gov). However, unlike lipid 
production on sugars provided in synthetic media, studies on yeast SCO production from biomass hydrolyzates are limited, and none have reported the expected yield of $0.2 \mathrm{~g}$ lipid/g sugar at volumetric productivities greater than $0.5 \mathrm{~g} / \mathrm{L} / \mathrm{h}$ expected to be needed for feasibility (Jin et al., 2015; Koutinas et al., 2014). As was the case for cellulosic ethanol production, pentose sugars and microbial inhibitors, including furfural, hydroxymethylfurfural, acetic acid, neutral and acidic phenolics, and other chemical species (Palmqvist and Hahn-Hägerdal, 2000a,b) are expected barriers to efficient conversion of biomass to lipids.

In this research, nine yeast genera having species known to accumulate large amounts of lipid (Ageitos et al., 2011; Heredia and Ratledge, 1988; Hu et al., 2011; Huang et al., 2012a,b,c; Li et al., 2008; Pan et al., 1986; Tsigie et al., 2011; Xie et al., 2012; Yu et al., 2011; Zhao et al., 2008), or related to known oleaginous yeast based on phylogeny (Kurtzman et al., 2011; Dien et al., 2016) were targeted for selecting strains to be screened to identify those with superior aptitude to produce lipid in hydrolyzates of biomass. Strains from the Agricultural Research Culture Collection were chosen from the following genera including Cryptococcus sp., Geotrichum sp., Lipomyces sp., Myxozyma sp., Rhodosporidium sp., Torulaspora sp., Trigonopsis sp., and Yarrowia sp. Additionally characterized in our screen was SCO production by Saitoella coloradoensis NRRL YB-2330 and Saitoella complicata NRRL Y-17804. These novel strains were recently noted by Kurtzman and Robnett (2012) to accumulate lipid granules and carotenoids, but lipid accumulation by these yeast had previously not been quantified. Many of the strains chosen for the screening were preferred because the species was noted in the above literature to use xylose, and several species were previously reported to function in detoxified hydrolyzates (Jin et al., 2015). Strains were screened in two tiers using two of the most commercially promising undetoxified hydrolyzates. The more benign ammonia fiber expansion-pretreated cornstover hydrolyzate (AFEX CSH) was the primary screening medium. The harsher switchgrass hydrolyzate (SGH), produced with a less costly state of the art dilute acid pretreatment, was the secondary screening medium applied to those strains passing the primary screen (Balan et al., 2009; Bothast and Saha, 1997; Jin et al., 2012; Lee et al., 1999). To provide the potential for commercially attractive lipid accumulation and production rates, hydrolyzates were prepared from biomass at $\sim 18-20 \%$ solids loading to yield over $100 \mathrm{~g} / \mathrm{L}$ sugars (at $\sim 56: 39: 5$ mass ratio glucose:xylose:arabinose) upon pretreatment and enzyme saccharification.

In AFEX CSH inhibitory sugar degradation product concentrations (i.e., furans) are low, and nitrogen from ammonia used in the pretreatment process as well as amino acids from the stover are available to support cell growth, resulting in the molar carbon to nitrogen ratio C:N $\sim 62: 1$ (Table I). In the enzyme hydrolyzates of dilute acid pretreated post-frost switchgrass, sugar degradation product concentrations are high and very little usable nitrogen is available, even from saccharification enzymes, resulting in $\mathrm{C}: \mathrm{N} \sim 500$. However, supplementation of nitrogen from sources of amino acids and ammonia could be used advantageously to control the C:N ratio in SGH (Table I). In theory, shifts of C:N to greater than 100:1 could more strongly trigger lipid production (Ageitos et al., 2011; Weete, 1980). Furthermore, Crabtree-negative yeasts, such as Lipomyces and Rhodosporidium species and others in our screen, are likely to be preferred for hydrolyzate utilization because they oxidize glucose and pentose sugars using aerobic metabolism via the pentose phosphate pathway; and relevant to process design, it is particularly important to recognize that increasing sugar concentration increases triacylglyceride accumulation in Crabtreenegative yeasts (Weete, 1980; Sitepu et al., 2013).

With this background in mind, best strains identified in screens were tested in a two-stage cultivation involving yeast cell production in the first stage on SGH formulated at 75\% concentration to lower inhibitor concentration and C:N $\sim 60: 1$ to favor growth, and subsequently lipid amplification in the second stage on nitrogenpoor hydrolyzates at much higher $\mathrm{C}: \mathrm{N} \sim 500: 1$ to favor lipid accumulation and limit growth. Based on nitrogen source optimization studies in hydrolyzate, the $\mathrm{C}: \mathrm{N}$ of $60: 1$ in the first stage was chosen to provide enough nitrogen to support abundant cell production and enough excess sugar after nitrogen depletion to initiate lipid accumulation. The C:N $\sim 500$ in the second stage was simply accepted as the lowest cost, unsupplemented SGH condition,

Table I. Compositions of hydrolyzates used in lipid production screens.

\begin{tabular}{|c|c|c|c|}
\hline Component & AFEX CSH $H^{\mathrm{a}, \mathrm{b}}$ & Dilute acid $\mathrm{SGH}^{\mathrm{a}}(\mathrm{N} \text {-amended })^{\mathrm{c}}$ & Dilute acid SGH (Unamended) \\
\hline Glucose $(\mathrm{g} / \mathrm{L})$ & $59.3 \pm 2.8$ & $65.8 \pm 5.1$ & $66.4 \pm 1.9$ \\
\hline Xylose (g/L) & $36.3 \pm 2.2$ & $49.8 \pm 2.9$ & $49.7 \pm 2.3$ \\
\hline Arabinose $(\mathrm{g} / \mathrm{L})$ & $5.6 \pm 0.5$ & $6.9 \pm 0.8$ & $7.1 \pm 0.8$ \\
\hline $\operatorname{HMF}^{\mathrm{a}}(\mathrm{mM})$ & 0.6 & $4.8 \pm 1.8$ & $1.7 \pm 0.9$ \\
\hline Furfural (mM) & 0.09 & $14.1 \pm 4.1$ & $15.0 \pm 2.8$ \\
\hline Acetic acid $(\mathrm{g} / \mathrm{L})$ & $2.4 \pm 0.3$ & $5.1 \pm 2.4$ & $4.1 \pm 1.3$ \\
\hline $\mathrm{PAN}^{\mathrm{a}}(\mathrm{mg} \mathrm{N} / \mathrm{L})$ & 293 & $288 \pm 65$ & $76.8 \pm 12.3$ \\
\hline $\mathrm{NH}_{3} \quad(\mathrm{mg} / \mathrm{L})$ & 563 & $705 \pm 115$ & $41 \pm 37$ \\
\hline Urea $(\mathrm{mg} / \mathrm{L})$ & 44 & $121 \pm 114$ & $14 \pm 3$ \\
\hline $\mathrm{C}: \mathrm{N}^{\mathrm{d}}$ & $62: 1$ & $62.4: 1 \pm 7.6$ & $513: 1 \pm 116$ \\
\hline
\end{tabular}

${ }^{\mathrm{a}} \mathrm{HMF}$, 5-hydroxymethyl furfural; PAN, primary amino nitrogen; AFEX CSH, ammonia fiber expansion-pretreated cornstover (6\% glucan loading); SGH, enzyme saccharified dilute acid pretreated switchgrass hydrolyzate (20\% solids loading).

${ }^{\mathrm{b}} \mathrm{A}$ common batch of AFEX CSH was used for screening all strains and only variations of initial sugar and acetic acid concentrations are represented.

${ }^{c}$ Nitrogen $(\mathrm{N})$ amendments included amino acids and $\left(\mathrm{NH}_{4}\right)_{2} \mathrm{SO}_{4}$.

${ }^{\mathrm{d}} \mathrm{C}: \mathrm{N}$ is the molar carbon to nitrogen ratio based on total useable sugars (glucose, xylose, and arabinose) and total available nitrogen ( $\mathrm{PAN}, \mathrm{NH}_{3}$, and urea). The contribution of acetic acid to the carbon supply was only $2-4 \%$ of that arising from sugars and was ignored in this calculation. 
that provided excess sugar for continued lipid accumulation instead of cell growth. Using the two-stage process, potential for very rapid and high lipid accumulations of $\sim 30 \mathrm{~g} / \mathrm{L}$ was demonstrated for promising oleaginous yeast strains on undetoxified hydrolyzates of dilute acid-pretreated switchgrass. This magnitude of lipid accumulation has not been previously reported in the literature, though single stage productions up to $15.8 \mathrm{~g} / \mathrm{L}$ using detoxified hydrolyzates of dilute-acid pretreated biomass have been noted (Jin et al., 2015). From the standpoint of efficient sugar usage, data were reported in terms of lipid yield per $g$ of sugar supplied and also per $g$ of sugar consumed in order to allow comparison of our two-stage process with other studies. From a process economics standpoint, the higher titer of lipid accumulated is a key factor in efficient recovery. The use of repitched cells to support a higher rate and yield of lipid production (with less sacrifice of carbon to cell growth) is also a key feature for streamlining the cost of operation. Given current hydrolysis technologies and the consequent limitations of microbial inhibitors, the concentration of sugars available in hydrolyzates is only around $120 \mathrm{~g} / \mathrm{L}$ (compared to $500 \mathrm{~g} / \mathrm{L}$ achievable in synthetic media) which in turn limits product concentrations, potentially raising recovery costs. Advantages of the two stage process over fed-batch operation are that it involves no dilution of the hydrolyzate sugar feed and at the same time provides a step shift up in both $\mathrm{C}: \mathrm{N}$ and sugar concentration to amplify lipid accumulation during the second stage of limited yeast growth. The data presented show the advantage of the two- stage batch process to allow accumulation of higher lipid concentrations faster than other types of batch processes recently reviewed by Jin et al. (2015).

\section{Materials and Methods}

\section{Preparation of AFEX CSH at $6 \%$ Glucan and SGH at $20 \%$ Solids Loading}

Corn stover, harvested in September 2008, was obtained from Arlington Research Station located in Wisconsin. The corn hybrid used in this study was Pioneer 36H56 (triple stack-corn borer/ rootworm/Roundup Ready) variety (Minneapolis, MN). Post frost switchgrass was obtained from the Kanlow N1 field, Mead, Nebraska, (USDA ARS Grain, Forage, and Bioenergy Research Unit, Lincoln, NE). AFEX CSH at $6 \%$ glucan and SGH at $20 \%$ solids loading were prepared as previously described without detoxification and were filter sterilized prior to inoculation with yeast (Slininger et al., 2015). As specified by experiment designs, the SGH was supplemented with $2.18 \mathrm{~g} / \mathrm{L}$ ammonium sulfate and $30 \mathrm{~g} / \mathrm{L}$ soy flour (Toasted Nutrisoy Flour Product, Archer Daniels Midland, Chicago, IL, code 063160) as a primary amino acids (PAN) source. Alternatively a vitamin-free casamino acids mix supplying $5.25 \mathrm{~g} / \mathrm{L}$ Bacto Difco Vitamin Assay Casamino Acids (Becton Dickinson, Franklin Lakes, NJ, no. 228830), 0.053 g/L D, L-tryptophan (Sigma, St. Louis, M0, T330-100G), and $0.209 \mathrm{~g} / \mathrm{L}$ L-cysteine (Sigma, C7352-100G) were added to SGH to supply equivalent PAN $(211 \mathrm{mg} \mathrm{N} / \mathrm{L})$ to the soy flour based on Megazyme kit assay (Wicklow, Ireland). Soy flour is the lowest cost source of amino acids commonly used in industrial cultivations $(\sim \$ 0.25 / \mathrm{lb})$. The casamino acids mix is a recommended combination to begin future optimization and design studies aimed at determining effective amino acid delivery to industrial processes (Zabriski et al., 1980). Table I compares the concentrations of key $\mathrm{C}$ and $\mathrm{N}$ sources and inhibitors found in each type of hydrolyzate prepared.

\section{Primary Screening of Yeast Strains on AFEX CSH}

Lyophilized cultures were obtained from the ARS Culture Collection (NCAUR, Peoria, IL) and stored in $20 \%(\mathrm{v} / \mathrm{v})$ glycerol at $-80^{\circ} \mathrm{C}$. Yeast strains and a control algae strain Chlorella sp. NRRL YB-3399 were streaked from glycerol stock cultures onto YM agar plates and incubated at $25^{\circ} \mathrm{C}$ for $48-96 \mathrm{~h}$, then refrigerated. Streak plates were transferred to fresh YM agar plates $24 \mathrm{~h}$ prior to pre-culture inoculation by loop. Precultures were incubated $48 \mathrm{~h}$ on $3 \%$ glucan AFEX CSH, which was prepared by diluting $6 \%$ glucan AFEX CSH 1:1 with water; and after concentrating precultures to an $\mathrm{A}_{620}$ of 50 , a $1 \%$ volume was transferred to inoculate the test cultures of $6 \%$ glucan AFEX CSH at pH 6 to an absorbance of 0.5 at $620 \mathrm{~nm}$ $\left(\mathrm{A}_{620}\right)$. Pre- and test cultures were incubated at $25^{\circ} \mathrm{C}, 400 \mathrm{rpm}$ shaking in deep, 96-well plates (System Duetz, Applikon, Delft, The Netherlands) filled $0.5 \mathrm{~mL}$ per well, then covered with standard aeration covers. Based on manufacturer data collected at $30^{\circ} \mathrm{C}$ and $300 \mathrm{rpm}$, the oxygen transfer rate of this system would be estimated to be at least $12 \mathrm{mM}$ oxygen/L/h under our incubation conditions. For test cultures, 24 wells per strain were blocked separately from other strains (1-2 empty rows between). For each time point, samples were drawn in duplicate by harvesting two micro-reactor wells, which were assayed for $\mathrm{A}_{620}$, sugar, nitrogen, and lipid.

\section{Secondary Screening of Strains on SGH}

Strains showing significant lipid accumulation ( $>5 \mathrm{~g} / \mathrm{L})$ on AFEX $\mathrm{CSH}$ were tested in a harsher secondary screen on $\mathrm{SGH}$ at $75 \%$ or $100 \%$ strength at $\mathrm{pH} 6$ versus $\mathrm{pH}$ 7. Stress on yeasts was increased by decreasing culture $\mathrm{pH}$ to further distinguish more robust strains. Switchgrass hydrolysate amended at $\mathrm{pH} 6$ with casamino acids was diluted to $50 \%$ concentration with sterile water for pre-cultures and inoculated by loop from $24 \mathrm{~h}$ YM plates prepared as described above. The inoculated pre-cultures were then incubated in deep, 96-well plates, as above for $48 \mathrm{~h}$. Once concentrated to an $\mathrm{A}_{620}$ of 50 in $\mathrm{pH} 7$ buffer, a $1 \%$ volume transfer was used to inoculate the test cultures 0.5 absorbance at $620 \mathrm{~nm}\left(\mathrm{~A}_{620}\right)$. Test cultures were prepared with $75 \%$ or $100 \%$ strength SGH at pH 6 or 7 such that each strain was tested on four SGH conditions increasing in harshness. For each strain, a deep 96-well plate was prepared, which contained 24 wells each of the four hydrolyzate types. Plates were incubated $\left(25^{\circ} \mathrm{C}, 400 \mathrm{rpm}\right)$ and sampled as described above.

\section{Amplified Lipid Production Using Two-Stage Cultivation on SGH}

Strains showing best performance in the secondary screen on SGH were further compared in a two-stage cultivation process at $\mathrm{pH}$ 7. In the first stage, yeast were grown on SGH cut to $75 \%$ (v/v) strength with water. The SGH was prepared as described below and had C:N 62 after nitrogen source amendments of soy flour $(30 \mathrm{~g} / \mathrm{L})$ and ammonium sulfate $(2.18 \mathrm{~g} / \mathrm{L})$. Eighty wells of a deep, 96-well plate 
were filled per strain: 40 were used to sample and monitor the growth stage, and 40 were used for the second stage re-suspension. For the second stage, yeast micro-cultures from the first stage 40 -well growth plate were combined and pelleted by centrifuging ( $15 \mathrm{~min}, 4500 \mathrm{rpm}$ ), and the pellets were resuspended in $20 \mathrm{~mL}$ of $100 \%$ strength SGH which had been prepared with no nitrogen source amendments such that C:N was 500-600. Then the $20 \mathrm{~mL}$ of resuspended culture was distributed $0.5 \mathrm{~mL}$ per each of 40 wells. Deep 96-well plates were incubated and sampled as above.

The impact of SGH strength (50-100\%), amino acids source (casamino acids vs. soy flour) and $\mathrm{pH}$ (6 vs. 7) were examined in a full factorial experiment design for impact on growth and lipid production of Lipomyces tetrasporus NRRL Y-11562 and Rhodosporidium toruloides NRRLY-1091 in the first stage growth cultures. The $50 \%$ and $75 \% \mathrm{v} / \mathrm{v}$ strengths of nitrogen-amended SGH were prepared from the full strength hydrolyzate $(100 \%)$ by dilution with distilled water. Soy flour (Toasted Nutrisoy Flour, product code 063160, ADM, Chicago, IL) or casamino acids (Difco VitaminAssay Casamino Acids, product code 228830, Becton Dickinson, Franklin Lakes, NJ) were applied to supply similar PAN levels for this study, although the balance of nitrogen was available mainly as ammonium sulfate with less than $10 \%$ from urea, as described for the full strength $\mathrm{N}$-amended dilute acid SGH (Table I). Stage 1 growth cultures were conducted in microplates as noted above. The ranges of variation in $\mathrm{pH}$ and hydrolyzate strength were chosen based on preliminary indications of tolerance during deep well plate tests suggesting the growth tolerance of each yeast.

The impacts of the molar carbon to nitrogen ratio C:N (25:1100:1), SGH strength (50-75\%), and soy flour amino acids (presence, absence) supplementation to ammonium nitrogen sources were next examined in a full factorial design with respect to growth and lipid production in first stage growth cultures of strains NRRL Y-1091 and NRRL Y-11562. C:N ratios were adjusted based on assays of usable nitrogen sources including PAN, ammonia, and urea. If PAN was not supplemented, its molar $\mathrm{N}$ contribution was replaced with added ammonium sulfate. Stage 1 and 2 cultures were done in microplates as above.

The performance of $L$. tetrasporus NRRL Y-11562 in a two-stage process was further explored by studying the impact of first stage growth culture variables SGH strength $(50 \%$ or $75 \%)$, soy amino acid amendment (presence or absence) and $\mathrm{pH}$ (6 or 7) at C:N 62:1 in combination with the second stage variable $\mathrm{pH}$ (6 or 7) in $100 \%$ SGH with no $\mathrm{N}$ amendment at C:N greater than 500:1. Using this design, variable impacts on yeast and lipid accumulation during first and second stage processes were determined.

The optimal two-stage cultivation process was also repeated for each successful strain at larger scale in flasks at $25^{\circ} \mathrm{C}$ in triplicate. Precultures of $50 \mathrm{~mL}$ volume were inoculated by loop into Bellco (Vineland, NJ) $250 \mathrm{~mL}$ baffled DeLong flasks (product SKU 254000250) with Bellco silicone closures (product SKU 2004-00005) and incubated with shaking at $300 \mathrm{rpm}$ for $72 \mathrm{~h}$. Precultures were concentrated to $\mathrm{A}_{620} 50$ in buffer at $\mathrm{pH}$ 7. A $1 \%(\mathrm{v} / \mathrm{v})$ inoculum was used to initiate yeast growth in $100 \mathrm{~mL}$ of $\mathrm{pH} 775 \%$ strength SGH amended with soy flour and ammonium sulfate to provide nitrogen levels consistent with Table I. The stage 1 "growth" cultures were incubated in Bellco $500 \mathrm{~mL}$ baffled DeLong flasks (product SKU $2540-00500)$ at $300 \mathrm{rpm}$ and sampled daily until all sugars were consumed. Once sugars were consumed, the growth culture cells were collected by centrifugation and re-suspended in $100 \mathrm{~mL}$ of pH 7 100\% strength SGH with no N amendment, as described above. The stage 2 "lipid amplification cultures" were then similarly incubated in $500 \mathrm{~mL}$ baffled flasks at $300 \mathrm{rpm}$ and sampled daily until all sugars were consumed. The pelleted cells from final cultures were ball milled to rupture cell walls and then extracted by the method of Bligh and Dyer (1959) to obtain the neutral lipid fraction for carotenoid and fatty acid profiling as described in the "Analyses" section below.

\section{Analyses}

Biomass concentration was measured by analyzing culture absorbance at $620 \mathrm{~nm}\left(\mathrm{~A}_{620}\right)$ in $1 \mathrm{~cm}$ path length cuvettes using an Evolution 60 spectrophotometer for the AFEX CSH primary screening or in 96-well microplate wells filled to $200 \mu \mathrm{L}$ using a Powerwave XS plate reader (BioTek, Winooski, VT) for the SGH secondary screening. Samples were diluted as needed to obtain absorbance in the linear range for each instrument. The absorbance readings from microplate wells were converted to equivalent cuvette values using the appropriate conversion factor to adjust for the difference in light path lengths. Dry cell weight concentrations were determined on select samples in addition to absorbance readings, by drying 1-2 $\mathrm{mL}$ of culture sample (washed and resuspended in distilled water) on a preweighed aluminum pan at $105^{\circ} \mathrm{C}$ for $24 \mathrm{~h}$.

Quantification of sugars, furfural, HMF, and acetic acid in culture samples was by a Waters HPLC system equipped with an HPX-87H Aminex ion exclusion column (Biorad Laboratories, Inc., Hercules, $\mathrm{CA}$ ) eluted at $60^{\circ} \mathrm{C}$ with $0.6 \mathrm{~mL} / \mathrm{min} 15 \mathrm{mM} \mathrm{HNO}_{3}$ as per details given in Slininger et al. (2015). For hydrolyzate compositional analysis, a Biorad Aminex HPX-87P carbohydrate analysis column (125-0098) was also eluted at $80^{\circ} \mathrm{C}$ with water mobile phase as per the detail in Slininger et al., 2015. For available nitrogen, enzymebased test kits were used to assay PAN, ammonia and urea (Megazyme International Ireland Ltd., Wicklow, Ireland). Molar $\mathrm{C}: \mathrm{N}$ ratio was calculated as the ratio of moles of carbon $(\mathrm{C})$ available in usable sugars (glucose, xylose, and arabinose) to the moles of usable nitrogen $(\mathrm{N})$ available (ammonia, urea, and amino acids).

Lipid production was measured periodically throughout the fermentation using the sulfo-phospho-vanillin (SPV) colorimetric assay on washed yeast cell pellets from $0.5 \mathrm{~mL}$ cultures. The SPV assay method was adapted from the literature (Izard and Limberger, 2003; Wang et al., 2009) as described in Dien et al. (2016) and standardized using corn oil. Along with the SPV assay, time-domain NMR was applied as an additional lipid measurement of select samples to confirm SPV assay consistence (Gao et al., 2008; Moreton, 1989). Analyses of extracted lipids by gas chromatography to determine fatty acid compostion and by gradient HPLC to determine the potential for carotenoid recovery were conducted as previously described (Hart and Scott, 1995; Ichihara et al., 1996; Rodriguez-Amaya, 2001). For details of these analyses and results, see supplemental data Tables SI and SII.

All samples are taken in at least duplicate for analysis. Analysis of variance (ANOVA) and Student Newman Keuls (SNK) pairwise comparison analyses were performed using Sigmastat 3.5 (Systat Software, Inc., San Hose, CA) at significance criterion $P \leq 0.05$. 


\section{Results and Discussion}

\section{Primary Screen of Yeast Strains on 6\% Glucan AFEX CSH}

As introduced earlier, the thirty-two yeast isolates obtained from the ARS Culture Collection were with few exceptions selected based on previously reported phenotypic qualities making them potentially good candidates for producing SCO from hydrolyzates, or relatedness to yeast strains known from the literature to possess such qualities. However, to the best of our knowledge the comparative lipid production by these strains had not been evaluated in undetoxified concentrated hydrolyzates of lignocellulosic biomass with sugar concentrations greater than $100 \mathrm{~g} / \mathrm{L}$. In our studies, hydrolyzates (adjusted to $\mathrm{pH}$ 6) were used as screening media without detoxification (such as by overliming). AFEX CSH at $6 \%$ glucan was applied as the primary screening medium since it was the more benign hydrolyzate with reduced sugar degradation products, such as furfural and HMF (Table I), compared to SGH. AFEX CSH, prepared using ammonia and supplied with amino acids from the stover, also had the advantage of being nitrogen sufficient, and no further $\mathrm{N}$ supplementation was applied. Table II lists the results of this primary screening, and out of the 32 potentially oleaginous strains, only 8 (or $25 \%$, names bolded) were able to accumulate greater than $5 \mathrm{~g} / \mathrm{L}$ lipids with productivities ranging from 0.06 to $0.1 \mathrm{~g} / \mathrm{L} / \mathrm{h}$. Figure 1 shows example time courses of top performing strains representing five yeast genera on AFEX CSH. All of the top strains were characterized by high levels of cell production on the AFEX CSH and also by the important ability to convert pentose sugars to product, a feature that has long been sought for the successful development of yeast for bioconversion of lignocellulose to ethanol (Hahn-Hägerdal et al., 2007; Jeffries and Jin, 2004; Prior et al., 1989; Slininger et al., 1982). Even the arabinose is used although delayed somewhat in the case of S. coloradoensis NRRL YB-2330. The ability to utilize arabinose is rarer in yeasts compared to xylose utilization. Additionally in this experiment, each isolate was exposed to $2.4 \pm 0.3 \mathrm{~g} / \mathrm{L}$ acetic acid upon inoculation, but in each case the acetic acid was completely

Table II. Comparative performance of isolates screened on AFEX CSH. ${ }^{a, b}$

\begin{tabular}{|c|c|c|c|c|c|c|}
\hline \multicolumn{3}{|c|}{ NRRL strain description } & \multicolumn{3}{|c|}{ Maximum values } & \multirow{2}{*}{$\frac{\text { Final }}{\text { Xylose }(\mathrm{g} / \mathrm{L})}$} \\
\hline Number & Genus & Species & $\mathrm{A}_{620}$ & Oil $(g / L)$ & Oil Rate (g/L/h) & \\
\hline YB-3399 & Chlorella & Sp. & 6.4 & 0.8 & 0.007 & 36.3 \\
\hline Y-1399 & Cryptococcus & aerius & $85.5 \pm 2.5$ & $9.8 \pm 0.4$ & $0.089 \pm 0.026$ & $0.5 \pm 0.6$ \\
\hline $3 C^{a}$ & Cryptococcus & flavescens & 14.0 & 0.6 & 0.004 & 37.6 \\
\hline OH71.4 $4^{\mathrm{a}}$ & Cryptococcus & flavescens & 40.7 & 1.4 & 0.015 & 27.7 \\
\hline $\mathrm{OH} 182.9^{\mathrm{a}}$ & Cyptococcus & flavescens & 47.4 & 1.5 & 0.015 & 17.7 \\
\hline Y-552 & Geotrichum & candidum & 36.2 & 1.1 & 0.021 & 0.0 \\
\hline Y-17921 & Lipomyces & arxii & NG & NG & NG & NG \\
\hline Y-27504 & Lipomyces & doorenjongii & 4.0 & 0.4 & 0.076 & 36.3 \\
\hline Y-7042 & Lipomyces & kononenkoae & 69.4 & 11.3 & 0.081 & 0 \\
\hline Y-11553 & Lipomyces & kononenkoae & 44.5 & 2.9 & 0.021 & 0 \\
\hline Y-11555 & Lipomyces & lipofer & 5.4 & 0.7 & 0.005 & 36.0 \\
\hline Y-17247 & Lipomyces & oligophaga & 2.8 & 0.1 & 0.001 & 36.7 \\
\hline Y-27493 & Lipomyces & starkeyi & 2.7 & 0.2 & 0.001 & 36.7 \\
\hline Y-27494 & Lipomyces & starkeyi & 3.0 & 0.2 & 0.002 & 36.7 \\
\hline Y-27495 & Lipomyces & starkeyi & 16.8 & 0.5 & 0.004 & 36.7 \\
\hline Y-11557 & Lipomyces & starkeyi & 60.8 & 3.0 & 0.022 & 3.8 \\
\hline Y-11562 & Lipomyces & tetrasporus & $86.9 \pm 10.3$ & $11.9 \pm 2.9$ & $0.100 \pm 0.0$ & $0.0 \pm \mathbf{0 . 0}$ \\
\hline Y-27496 & Lipomyces & tetrasporus & 50.2 & 0.5 & 0.003 & 0.1 \\
\hline Y-27497 & Lipomyces & tetrasporus & 11.8 & 3.5 & 0.017 & 0.0 \\
\hline Y-17252 & Myхоzуmа & geophila & 46.0 & 1.9 & 0.021 & 0.0 \\
\hline Y-17253 & Myxozyma & lipomycoides & 17.6 & 0.8 & 0.009 & 0.8 \\
\hline Y-11823 & Myхоzyma & mucilagina & 42.1 & 1.8 & 0.021 & 0.0 \\
\hline Y-17387 & Myхоzyma & udenii & 62.4 & 2.5 & 0.019 & 0.0 \\
\hline Y-17727 & Myхоzyma & vanderwaltii & 62.7 & 2.4 & 0.026 & 0.0 \\
\hline Y-7903 & Pichia & nakazawae & 68.6 & 3.2 & 0.050 & 0.7 \\
\hline Y-1091 & Rhodosporidium & toruloides & $93.8 \pm 5.8$ & $8.8 \pm 2.3$ & $0.095 \pm 0.023$ & $0.2 \pm \mathbf{0 . 3}$ \\
\hline Y-63011 & Torulaspora & delbrueckii & 46.2 & 2.0 & 0.034 & 24.5 \\
\hline Y-7986 & Torulaspora & delbrueckii & 56.2 & 1.4 & 0.031 & 11.7 \\
\hline Y-1579 & Trigonopsis & variabilis & 77.5 & 2.4 & 0.035 & 0.6 \\
\hline YB-387 & Yarrowia & lipolytica & 97.2 & 2.5 & 0.053 & 0.8 \\
\hline YB-392 & Yarrowia & lipolytica & 86.4 & 5.8 & 0.096 & 0.4 \\
\hline YB-419 & Yarrowia & lipolytica & 89.2 & 3.2 & 0.058 & 0.9 \\
\hline YB-423 & Yarrowia & lipolytica & 77.4 & 3.4 & 0.069 & 0.0 \\
\hline YB-437 & Yarrowia & lipolytica & 76.0 & 5.8 & 0.061 & 0.6 \\
\hline YB- 2330 & Saitoella & coloradoensis & 67.4 & 8.5 & 0.071 & 2.5 \\
\hline Y-17804 & Saitoella & complicata & 74.3 & 7.4 & 0.067 & 1.8 \\
\hline
\end{tabular}

${ }^{\text {a }}$ Strains useful as biological control agents were received from Dr. David Schisler, NCAUR, Peoria, IL.

${ }^{b}$ Embolding highlights strains that were able to accumulate $>5 \mathrm{~g} / \mathrm{L}$ lipid on the AFEX CSH and were subsequently subjected to a secondary screen on SGH with $20 \%$ solids loading; NG indicates no growth. 
A Lipomyces tetrasporus NRRL Y-11562

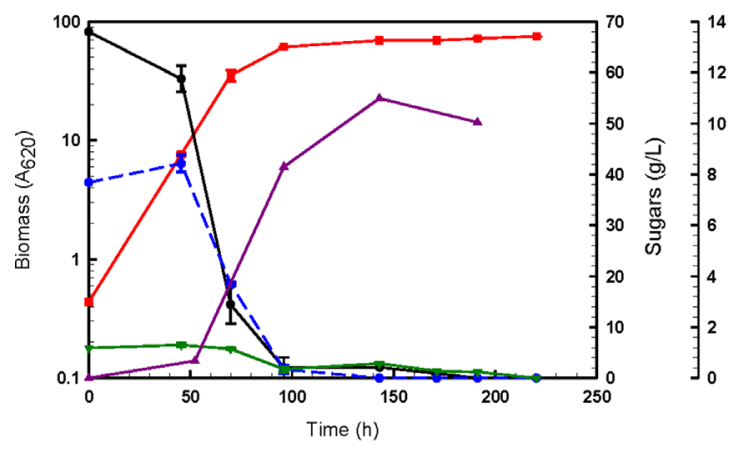

C Cryptococcus aerius NRRL Y-1399

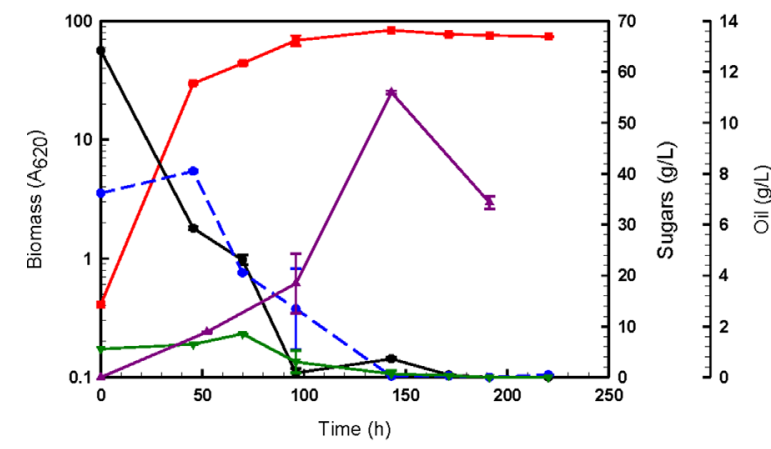

E Rhodosporidium toruloides NRRL Y-1091

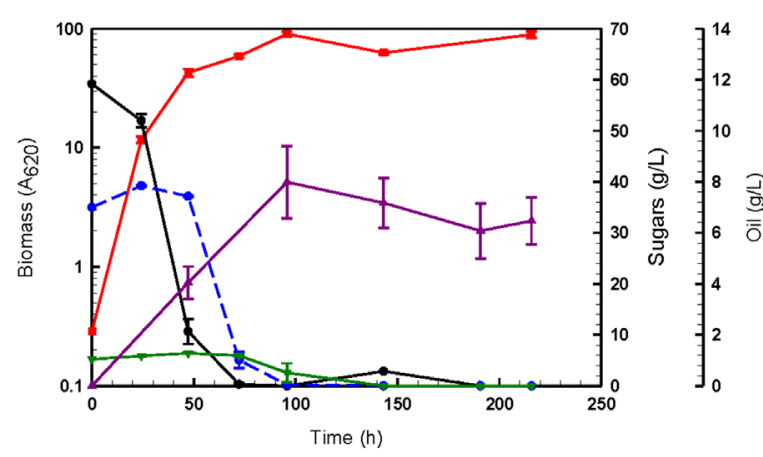

B Lipomyces kononenkoae NRRL Y-7042

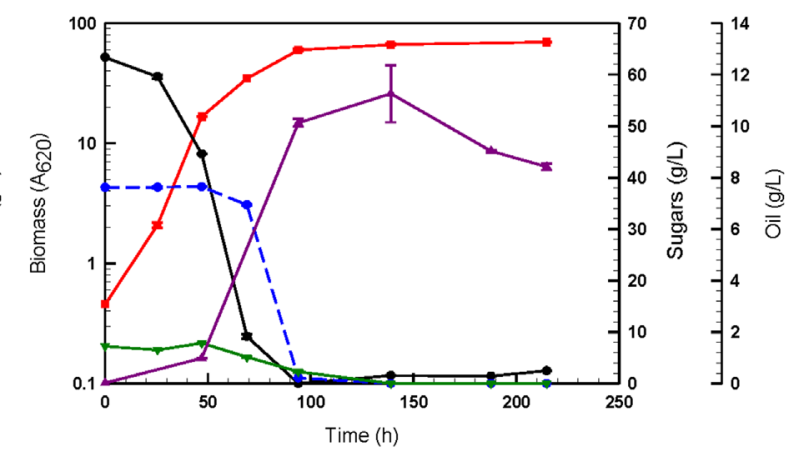

Saitoella coloradoensis NRRL YB-2330

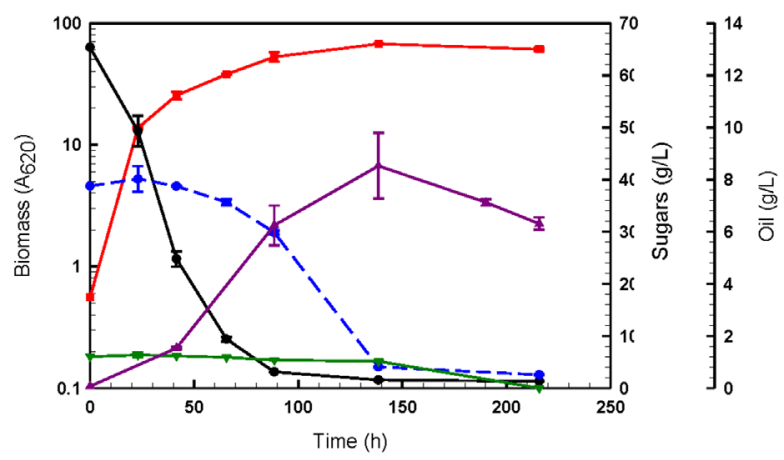

F Yarrowia lipolytica YB-392

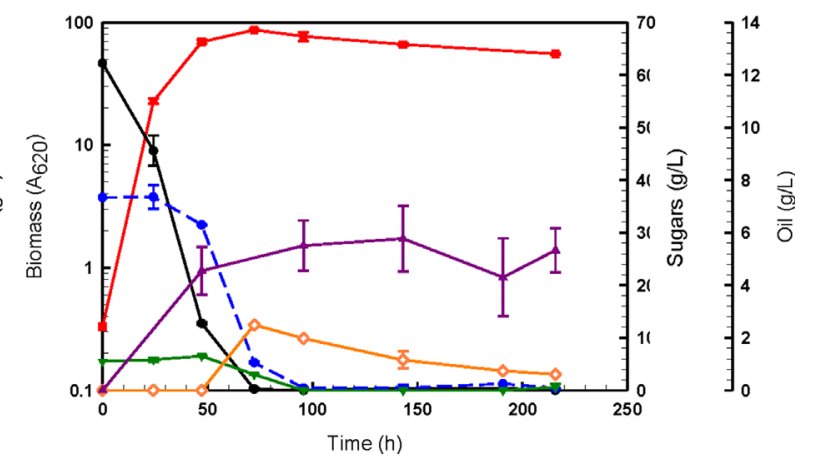

Figure 1. Bioconversion time courses of top lipid-producing yeasts from five genera utilizing sugars in $6 \%$ glucan AFEX CSH during screening in 96 -well deep well plates: (A) Lipomyces tetrasporus NRRL Y-11562; (B) Lipomyces kononenkoae NRRL Y-7042; (C) Cryptococcus aerius NRRL Y-1399; (D) Saitoella coloradoensis NRRL Y-2330; (E) Rhodosporidium toruloides NRRL Y-1091; and (F) Yarrowia lipolytica NRRL YB-392. Red squares represent biomass ( $A_{620}$ ), black circles with solid line are glucose, blue circles with dashed line are xylose, open orange diamonds with solid line are xylitol, inverted green triangles are arabinose, and purple triangles are lipid. Error bars represent the range about the mean shown by symbols.

consumed before the sampling was done at $48 \mathrm{~h}$ (data points not shown). This finding is very encouraging since any inhibition posed by acetic acid was rapidly neutralized during early yeast growth. The best of the lipid-producing strains on AFEX CSH based on lipid accumulation included the following (in order of rank): L. tetrasporus NRRL Y-11562, L. kononenkoae NRRL Y-7042> C. aerius NRRL Y-1399 $>$ S. coloradoensis NRRL YB-2330, R. toruloides NRRL Y-1091 > Y. lipolytica NRRL YB-392, -437. Species of the genus Saitoella, strains S. coloradoensis NRRL
YB-2330 and S. complicata NRRL Y-17804 also did well on AFEX $\mathrm{CSH}$ and have not been previously characterized with respect to their lipid producing capability. These are the only two species of the rarely isolated genus Saitoella as reported previously in the taxonomic study of Kurtzman and Robnett, (2012), yet the potential value of this genus for lipid production from biomass is demonstrated by its successful conversion of AFEX CSH to lipids.

In a separate study, twenty-two of the same strains were screened in baffled flasks on a synthetic lipid production medium 
supplemented with $100 \mathrm{~g} / \mathrm{L}$ glucose, with a focus on species of the genera Lipomyces and Myxozyma relative to representatives of the genera Cryptococcus, Rhodosporidium, Torulaspora, Trigonopsis, and Yarrowia (Dien et al., 2016). Of these, 14 of 22 (or 63\%) produced greater than $5 \mathrm{~g} / \mathrm{L}$ lipids. Thus the hydrolyzate screen was considerably more selective, as was expected, because of increased pressure by inhibitors. The top seven of fourteen (50\%) of the lipid producing strains on synthetic medium based on lipid accumulation included L. tetrasporus NRRL Y-11562 $>$ L. kononenkoae NRRL Y-7042 $>$ L. lipofer NRRL Y-11555 $>R$. toruloides NRRL Y-1091 > L. starkeyi NRRLY-27495, NRRL Y-27494 > L. tetrasporus NRRL Y-27496. Three of the four top strains for converting AFEX $\mathrm{CSH}$ to lipid were also among the top four strains on synthetic medium, but three of the top seven strains on synthetic medium NRRL Y-11555, Y-27495, Y-27494 did not grow on AFEX CSH, and a fourth strain NRRL Y-27496 grew well and utilized xylose but did not produce lipid on this hydrolyzate. No strains were found that performed poorly on synthetic medium but well on AFEX CSH.

From these observations, some guidelines on screening efficiency are suggested. The use of microreactors in the form of 96-well deep well plates specially designed to achieve high oxygen transfer rates offers a rapid method of screening strains for lipid production in replicate in small quantities of any culture medium, a feature especially helpful if working with limited quantities of hydrolyzate. The high aeration rate allows for the production of high cell densities and high volumetric productivities such that lipid accumulations peak in 4-6 days or less, even on inhibitory hydrolyzates. Use of hydrolyzate as a first round screening medium may be manageable in such aerobic micro-reactors and may additionally be the most expeditious if the specific goal is to identify the most robust strains for lipid production from hydrolyzate sugars that are low cost, but accompanied by fermentation inhibitors. One constraint on screening efficiency is the tedious evaluation of lipid concentration. However, the lack of growth on hydrolyzate is a criterion for quickly winnowing out undesirable strains and reducing samples for lipid processing. Additionally, since our hydrolyzates contain abundant pentose sugars, especially xylose, and arabinose along with glucose, the pentose use criterion could be applied to minimize the lipid analysis burden. Of the thirty-two potential oleaginous yeast strains screened, lipid analyses on about one third of these strains could be eliminated based on poor growth and/or poor xylose utilization. Efficient pentose utilization is required for the rapid conversion of mixed sugars in lignocellulose to the high yield of lipid required for favorable economics. Xylose and arabinose utilization following glucose uptake was frequently, but not always observed among strains of each of the genera that we tested. Some yeast, such as Yarrowia lypolytica are reported as not utilizing xylose as the sole carbon source on defined media (Kurtzman et al., 2011). However, we observed five strains of this type to completely use the xylose available in AFEX CSH (Table I). For example, Y. lipolytica NRRL YB-392 is shown in Figure 1F to convert xylose to lipid with transient accumulation of the intermediate xylitol following glucose consumption. This finding indicated the practical importance of screening for xylose use on the mixed sugars present in hydrolyzates rather than on xylose alone as the sole carbon source. It is also a key point that phylogenetic relatedness described in Kurtzman et al. (2011) can be used to further choose related strains for testing once good oleaginous strains robust to hydrolyzate applications are identified. For example, based on the exceptional performance of $L$. tetrasporus NRRL Y-11562 in hydrolyzates, other closely related strains were selected for testing. L. kononenkoae NRRL Y-7042 was thus identified for screening in hydrolyzate as a close relative to strain Y-11562 and, as a result, was found to be a rival for best performance on the hydrolyzate. In a prior separate study, the concept of expanding the range of screening around highperforming oleaginous species was proven by Dien et al. (2016) using a synthetic media study where strain L. kononenkoae NRRL Y-7042 and others were shown to perform similarly to L. tetrasporus NRRL Y-11562. Although significantly fewer of the high-performing strains in the synthetic medium were successful in the hydrolyzate screening, the best-performing strains in hydrolyzate were close phylogenetic relatives.

It is notable that the control algae tested, Chlorella sp. strain NRRL YB-3399, was not as well suited to conversion of the AFEX $\mathrm{CSH}$ to lipid as were the better yeast species screened. These accumulated 11-14.8 times more SCO than the Chlorella sp. strain NRRL YB-3399 and at 12.7-14.3 times the volumetric SCO productivity. The observed kinetic performance of our Chlorella sp. control is consistent with other reports on lipid production by algae, and this side-by-side comparison further justifies the suitability of yeast relative to algae for converting biomass hydrolyzates to SCO for biodiesel fuel: yeast can support higher and faster SCO titers coupled with the potential for less contamination by competing bacteria or phages.

\section{Secondary Screen of Yeast Strains on SGH (20\% Solids Loading)}

All eight isolates able to produce greater than $5 \mathrm{~g} / \mathrm{L}$ lipid on the primary screen on AFEX CSH (embolded in Table II) were subjected to a secondary screen on switchgrass hydrolyzates (SGH) prepared using dilute-acid pretreatment of biomass at the $20 \%$ solids loading (Table I). Compared with AFEX CSH, the dilute acid -pretreated SGH contained higher concentrations of microbial inhibitors, including acetic acid, furfural, and 5-hydroxymethyl furfural (HMF) (Table I). The severity of SGH exposure was modulated by applying it at both $75 \%$ and $100 \%$ of full strength and at initial pH 6 versus $\mathrm{pH} \mathrm{7,} \mathrm{resulting} \mathrm{in} \mathrm{four} \mathrm{levels} \mathrm{of} \mathrm{inhibitor} \mathrm{severity.} \mathrm{Initial}$ culture $\mathrm{pH}$ at 6 , as compared to 7 , increases the impact of acetic acid on cells due to the higher equilibrium hydronium ion concentration (Casey et al., 2010). Operation at acidic pH is desired to prevent contaminants from gaining a foothold in the hydrolyzates and competing for sugar, potentially resulting in undesired products and even stalled cultures. Table III summarizes the comparative performances of the four isolates able to grow and produce significant lipid on at least one of the four SGH conditions. Four other isolates were unsuccessful at colonizing any of the SGH formulations and are not shown here. Both L. tetrasporus NRRL Y-11562 and L. kononenkoae NRRL Y-7042 were able to produce lipids in SGH at accumulations and rates approaching those observed in AFEX CSH (Table II). Although strain NRRL Y-7042 maintained similar lipid accumulations and productivities across all four SGH severities, it generally exhibited similar, but somewhat 
Table III. Comparative performances of isolates ${ }^{\mathrm{a}}$ in a secondary screen on N-amended dilute acid-pretreated SGH ${ }^{\mathrm{b}}$ at C:N 62:1.

\begin{tabular}{|c|c|c|c|c|c|c|c|}
\hline \multirow[b]{2}{*}{ Species } & \multirow[b]{2}{*}{ Strain (NRRL) } & \multirow[b]{2}{*}{ SGH strength (\%) } & \multirow[b]{2}{*}{$\mathrm{pH}^{\mathrm{d}}$} & \multirow[b]{2}{*}{ Maximum biomass $\left(\mathrm{A}_{620}\right)$} & \multicolumn{3}{|c|}{ Maximum lipid ${ }^{\mathfrak{c}}$} \\
\hline & & & & & Concentration $(\mathrm{g} / \mathrm{L})$ & Productivity $(\mathrm{g} / \mathrm{L} / \mathrm{h})$ & Yield $(\mathrm{g} / \mathrm{g})$ \\
\hline \multirow[t]{4}{*}{ Rhodosporidium toruloides } & Y-1091 & 75 & 7 & 48.9 & 7.9 & 0.066 & 0.085 \\
\hline & & & 6 & 0.46 & 0 & 0 & 0 \\
\hline & & 100 & 7 & 0.45 & 0 & 0 & 0 \\
\hline & & & 6 & 0.61 & 0 & 0 & 0 \\
\hline \multirow[t]{4}{*}{ Lipomyces tetrasporus } & Y-11562 & 75 & 7 & 52.9 & 11.7 & 0.110 & 0.124 \\
\hline & & & 6 & 44.6 & 11.4 & 0.109 & 0.131 \\
\hline & & 100 & 7 & 53.4 & 12.1 & 0.072 & 0.099 \\
\hline & & & 6 & 21.4 & 6.6 & 0.038 & 0.054 \\
\hline \multirow[t]{4}{*}{ Lipomyces kononenkoae } & Y-7042 & 75 & 7 & 42.1 & 7.03 & 0.059 & 0.079 \\
\hline & & & 6 & 41.4 & 6.5 & 0.070 & 0.074 \\
\hline & & 100 & 7 & 43.2 & 10.8 & 0.065 & 0.091 \\
\hline & & & 6 & 46.5 & 9.5 & 0.057 & 0.079 \\
\hline \multirow[t]{4}{*}{ Saitoella coloradoensis } & YB-2330 & 75 & 7 & 29.4 & 7.3 & 0.043 & 0.078 \\
\hline & & & 6 & 0.52 & 0 & 0 & 0 \\
\hline & & 100 & 7 & 0.52 & 0 & 0 & 0 \\
\hline & & & 6 & 0.73 & 0 & 0 & 0 \\
\hline
\end{tabular}

${ }^{\mathrm{a}}$ Isolates listed are only those passing the primary screen on 6\% glucan AFEX CSH which also produced significant lipid on SGH.

${ }^{\mathrm{b}}$ Values are the average of 2-4 replicate runs.

${ }^{c}$ Values are calculated at the time of maximum lipid accumulation. Lipid productivity was calculated as the maximum lipid concentration divided by the corresponding time. The lipid yield was calculated as the lipid concentration formed per the total usable sugar concentration (glucose, xylose, and arabinose) supplied to the culture.

${ }^{\mathrm{d}}$ Initial $\mathrm{pH}$ of 6 or 7 was set for batch cultures, but not controlled.

lower accumulations and rates than did NRRL Y-11562, with the exception of the most severe SGH formulation (100\% SGH at pH 6) in which it outperformed NRRL Y-11562. R. toruloides NRRLY-1091 and S. coloradoensis NRRL YB-2330 grew and produced lipid on the lowest severity SGH formulation, but not on the other three which were too inhibitory for growth.

\section{Two Stage Lipid Production on SGH Allowing Rapid Amplification of Lipids in Yeasts}

The batch culture results listed in Table III suggest that the lipid productivity and yield of the four most robust stains may be increased by reducing the SGH strength from $100 \%$ to $75 \%$. This reduction in strength corresponds to a reduction of the microbial inhibitors present, but also caused a lower lipid titer commensurate with the dilution of sugars. A two-stage process was hypothesized to maximize both the efficiency and amount of lipid accumulation. L. kononenkoae NRRL Y-7042, L. tetrasporus NRRL Y-11562, and R. toruloides NRRL Y-1091 were each grown in both $75 \%$ and $100 \%$ strength SGH at C:N 62:1 in order to confirm the impact of SGH strength on first stage cell growth and lipid production kinetics. Yeasts were harvested once glucose and xylose had fallen to zero and then resuspended in $100 \%$ SGH with no nitrogen supplementation, that is, $\mathrm{C}: \mathrm{N} \sim 600$, the goal being to amplify lipid accumulation in essentially non-growing stationary phase cells. It has been reported that high hydrolyzate concentrations are more inhibitory toward yeast growth than toward ethanologenic fermentation processes (Palmqvist and Hahn-Hägerdal, 2000a,b). We hypothesized that fatty acid biosynthesis would also be more robust to inhibitors than growth, allowing for use of the more severe, undiluted hydrolyzate. Furthermore, eliminating the need to support growth in the second stage was compatible with the goal of utilizing full strength SGH that had very high C:N (typically limiting growth due to $\mathrm{N}$ starvation) in order to enhance yeast lipid productivity and yield. Figures 2 and 3 depict results for $L$. tetrasporus, L. kononenkoae, and R. toruloides which indicate that high lipid accumulations of $20 \mathrm{~g} / \mathrm{L}$ or more could indeed be accumulated very rapidly in a second stage cultivation to amplify lipid concentration in the yeast population after propagation was mainly completed in the first stage growth on SGH at a lower, less inhibitory concentration such as $75 \%$. The culture time courses shown in Figure 2 confirm that when compared with growth on $100 \% \mathrm{SGH}$, the growth of both of the Lipomyces strains on $75 \%$ SGH allowed more rapid and higher yielding lipid production in the second stage cultivation on $100 \%$ SGH at C:N 600:1. Figure 3 displays the results of applying a similar cultivation scheme to $R$. toruloides NRRL Y-1091. In this case, the growth of strain NRRL Y-1091 was completely inhibited by the $100 \%$ SGH, and thus only the 75\% SGH growth result is shown.

\section{Optimization of the Two-Stage Process for Growth and Lipid Amplification}

The sensitivity of the first stage growth cultures to amino acids source (casamino acids vs. soy flour at equal PAN content), SGH strength (50\%, 75\%, and $100 \%)$, and initial $\mathrm{pH}$ (6 vs. 7) was further assessed for $R$. toruloides NRRLY-1091 and L. tetrasporus NRRL Y-11562. Of these variables, the impact of SGH strength was of greatest impact and statistical significance on product accumulations $(P<0.001)$ as indicated by the results of a three-way ANOVA (Table IV). The 75\% SGH allowed highest $96 \mathrm{~h}$ cell and lipid accumulation for strain NRRL Y-1091 which was fully inhibited by $100 \%$ SGH. Lipid production followed similar trends to cell growth with respect to SGH strength. For L. tetrasporus NRRL Y-11562 the trends for cell and lipid accumulations were similar to those of NRRL Y-1091 at $96 \mathrm{~h}$, but eventual cell and lipid accumulations at $165 \mathrm{~h}$ were highest for strain NRRL Y-11562 on $100 \%$ SGH, 
Stage 1

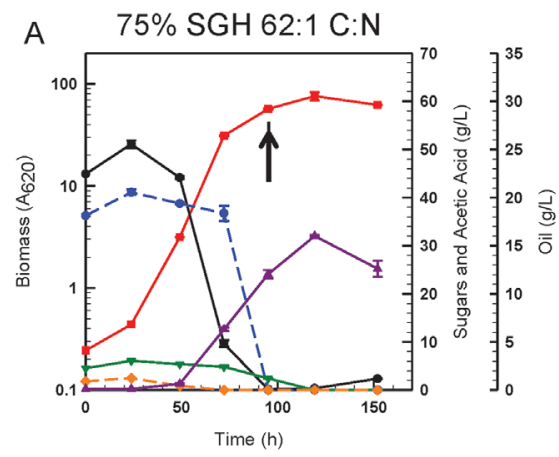

B $\quad 100 \%$ SGH $62: 1 \mathrm{C:N}$

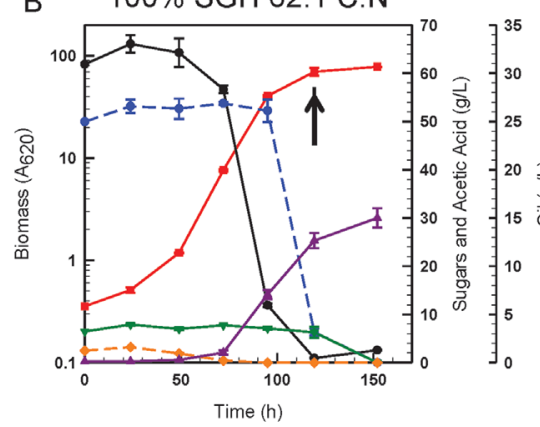

Stage 1
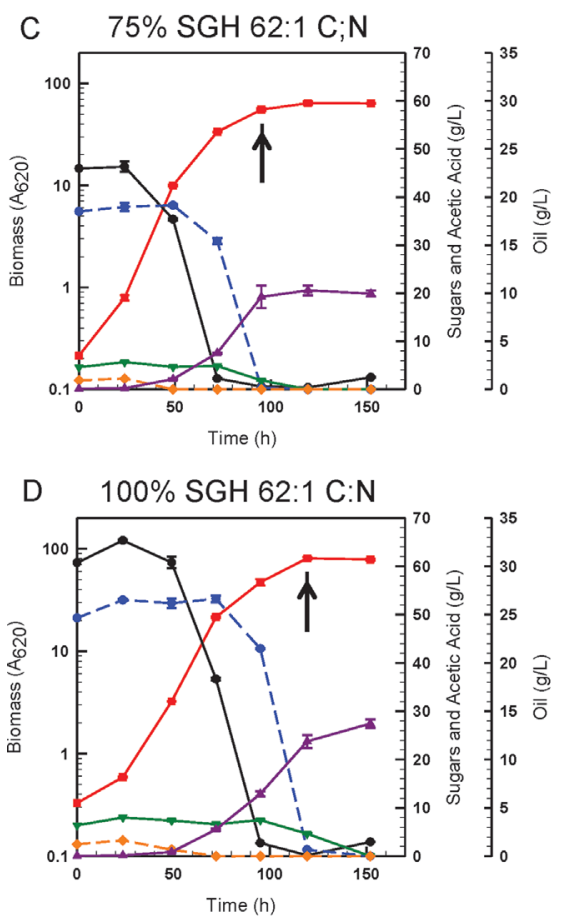

Stage 2

100\% SGH 600:1 C:N

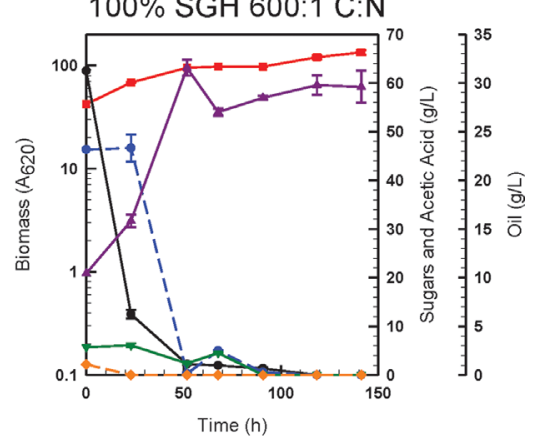

100\% SGH 600:1 C:N

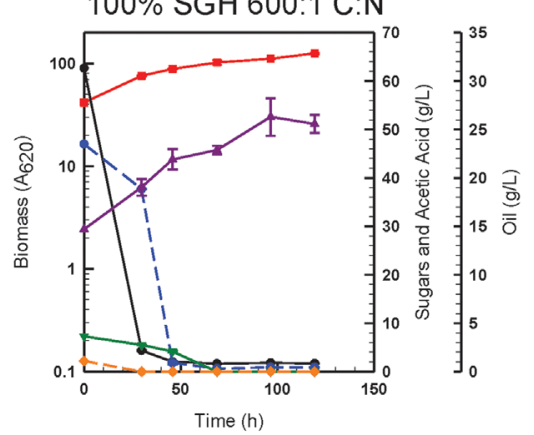

Stage 2
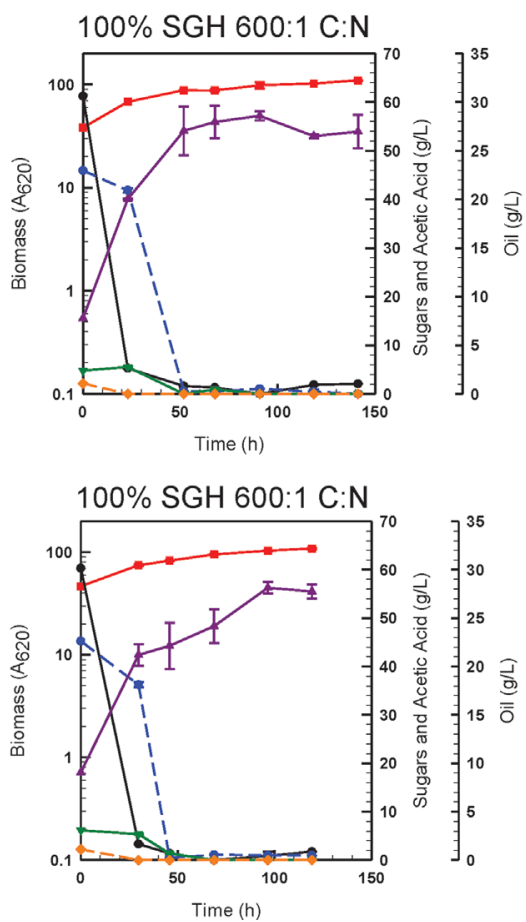

Figure 2. Lipomyces tetrasporus NRRL Y-11562 (A and B) and Lipomyces kononenkoae NRRL Y-7042 (C and D) lipid accumulations in two-stage processes at pH 7 involving growth on either 75\% SGH (A and C) or on 100\% SGH (B and D) at C:N 62:1 followed by resuspension of each cell population in 100\% SGH prepared with no N amendment for C:N 600:1. All cultivations were carried out in 96 -well deep well plates. Red squares represent biomass $\left(A_{620}\right)$, black circles with solid line are glucose, blue circles with dashed line are xylose, green inverted triangles are arabinose, gold diamonds are acetic acid, and purple triangles are lipid. The arrow marks the growth stage time course point of cell harvest. Note that cultures monitored during the growth phase (left), were replicates of those harvested to resuspend in the lipid amplification stage shown (right). Error bars represent the range about the mean shown by symbols. 
Stage 1

$75 \%$ SGH 62:1 C:N

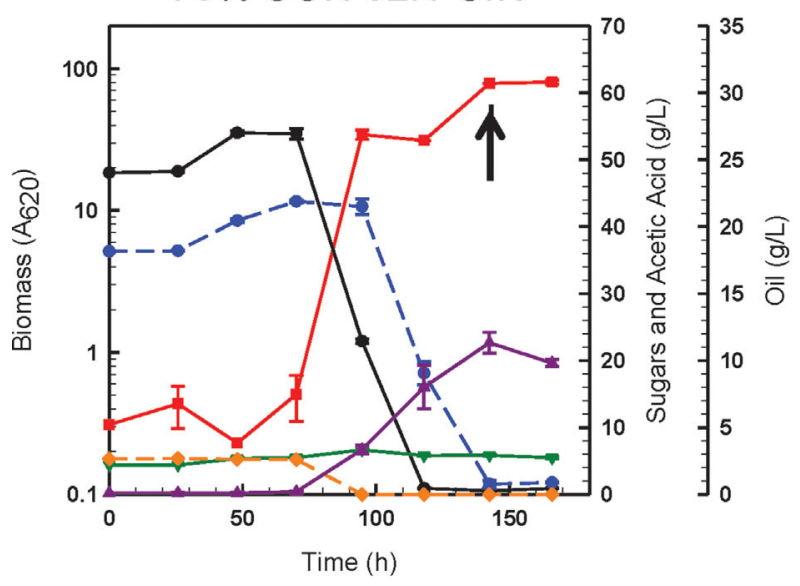

Stage 2

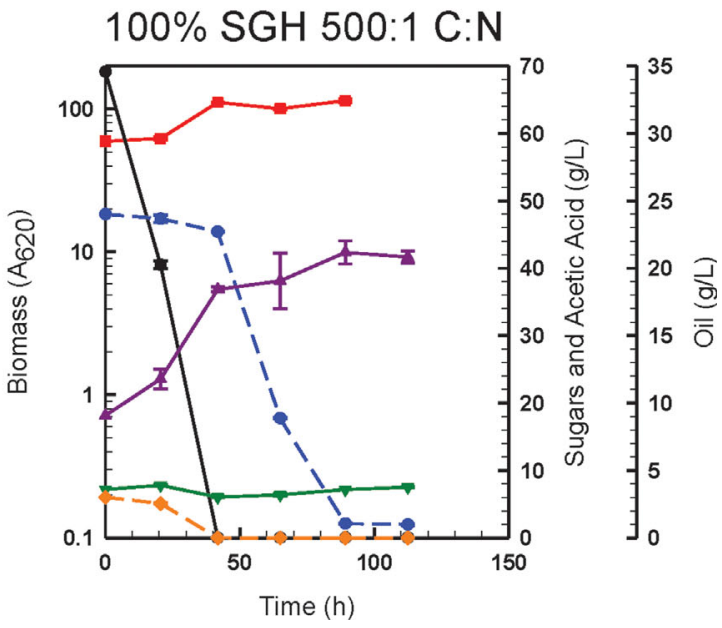

Figure 3. Rhodosporidium toruloides NRRL Y-1091 lipid accumulations in a two-stage process at pH 7 involving growth on $75 \%$ SGH at C:N $62: 1$ followed by resuspension of the cell population in $100 \%$ SGH prepared with no $\mathrm{N}$ amendment for C:N 600:1. All cultivations were carried out in 96-well deep well plates. Red squares represent biomass ( $\mathrm{A}_{620}$ ), black circles with solid line are glucose, blue circles with dashed line are xylose, green inverted triangles are arabinose, gold diamonds are acetic acid, and purple triangles are lipid. The arrow marks the growth stage time course point of cell harvest. Note that cultures monitored during the growth phase (left), were replicates of those harvested to resuspend in the lipid amplification stage shown (right). Error bars represent the range about the mean shown by symbols.

suggesting its higher inhibitor tolerance compared to NRRL Y-1091. The impacts of the other variables tested, that is, amino acids source and $\mathrm{pH}$, were not significant.

In another complete factorial experiment the impacts of $\mathrm{C}: \mathrm{N}$ ratio (25-100:1), SGH strength $(50 \%$ or $75 \%)$, and soy flour (presence or absence) on growth and lipid production in first stage cultures were studied using strains NRRL Y-1091 and Y-11562. In this experiment the $75 \%$ hydrolyzate strength was significantly more inhibitory to early growth and lipid production by NRRL Y-1091 at all C:N levels compared with the 50\% hydrolyzate strength. In the absence of soy flour, the average cell accumulations $\left(\mathrm{A}_{620}\right)$ for strain NRRL Y-1091 at $68 \mathrm{~h}$ were 31 for $50 \% \mathrm{SGH}$, compared to nearly 0 for $75 \%$ SGH, but $\mathrm{A}_{620}$ reached 37 compared with 17 , respectively, when soy flour was supplemented (data not shown). There was no significant difference in cell accumulations of NRRL Y-11562 in 50 and 75\% SGH, regardless of soy flour supplementation. Figure 4 shows the impact of C:N, and soy flour on lipid accumulation for both strains in the 75\% strength SGH. Inclusion of soy flour as PAN source and increasing C:N from 25 to over 50 dramatically increased early growth for NRRL Y-1091, and supported higher eventual biomass accumulations in the 75\% SGH (Fig. 4A and C). The early growth rate of NRRL Y-11562 was also improved with soy flour supplementation, but the eventual biomass accumulation was not very sensitive to C:N greater than 25 (Fig. 4B and D). The 75\% strength hydrolyzates generally allowed higher eventual lipid accumulations than did 50\% strength hydrolyzates, but only if soy flour was provided to supply PAN and potentially other growth factors (data not shown). Additionally oil accumulation increased significantly with increasing $\mathrm{C}: \mathrm{N}$ for both yeast strains (Fig. 4E-H). For NRRL Y-11562 oil accumulation reached a plateau of $\sim 10 \mathrm{~g} / \mathrm{L}$ lipid at around $75 \mathrm{C}: \mathrm{N}-\mathrm{a}$ feature which was more clearly discernible in the data with soy flour included (Fig. 4F).

Based on results of first stage growth studies, a number of trends were suggested. First $75 \%$ strength SGH appears to be preferred over $50 \%$ or $100 \%$ SGH because it supported rapid growth, high cell densities and abundant lipid accumulations if appropriate amino acid supplements were applied, that is, in the form of soy flour or

Table IV. Significant impact of SGH strength at C:N 62:1 on product accumulations in oleaginous yeast strains.

\begin{tabular}{|c|c|c|c|c|c|c|c|c|c|}
\hline \multirow[b]{2}{*}{ SGH Strength $(\%)$} & \multicolumn{3}{|c|}{ R. toruloides NRRL Y-1091 least square means ${ }^{\mathrm{a}}$} & \multicolumn{6}{|c|}{ L. tetrasporus NRRL Y-11562 least square means ${ }^{\mathrm{a}}$} \\
\hline & $A_{620}$ & at $96 \mathrm{~h}(-)$ & Lipids at $96 \mathrm{~h}(\mathrm{~g} / \mathrm{L})$ & $A_{620}$ & at $96 \mathrm{~h}(-)$ & $\mathrm{A}_{620}$ & at $165 \mathrm{~h}(-)$ & Lipids at $96 \mathrm{~h}(\mathrm{~g} / \mathrm{L})$ & Lipids at $165 \mathrm{~h}(\mathrm{~g} / \mathrm{L})$ \\
\hline 50 & & $28.0 \mathrm{~A}$ & $6.04 \mathrm{~B}$ & & $19.4 \mathrm{AB}$ & & $36.0 \mathrm{~B}$ & $6.50 \mathrm{~B}$ & $6.57 \mathrm{C}$ \\
\hline 75 & & $29.3 \mathrm{~A}$ & $7.67 \mathrm{~A}$ & & $22.4 \mathrm{~A}$ & & $50.2 \mathrm{~B}$ & $9.48 \mathrm{~A}$ & $9.53 \mathrm{~B}$ \\
\hline 100 & & $0.4 \mathrm{~B}$ & $0 \mathrm{C}$ & & $15.4 \mathrm{~B}$ & & $71.7 \mathrm{~A}$ & $4.79 \mathrm{C}$ & $14.00 \mathrm{~A}$ \\
\hline Standard error & & 0.8 & 0.038 & & 0.5 & & 1.6 & 0.06 & 0.11 \\
\hline
\end{tabular}

${ }^{\mathrm{a}}$ Means with no letters in common indicate significance differences at the $P=0.001$ significance level based on Student-Newman-Keuls pairwise comparison method. Reported means were averages across test $\mathrm{pH} 6$ and 7 and the different types of amino acids sources since these parameters were not significant sources of variation $(P>0.05)$ based on the three-way analysis of variance performed. 

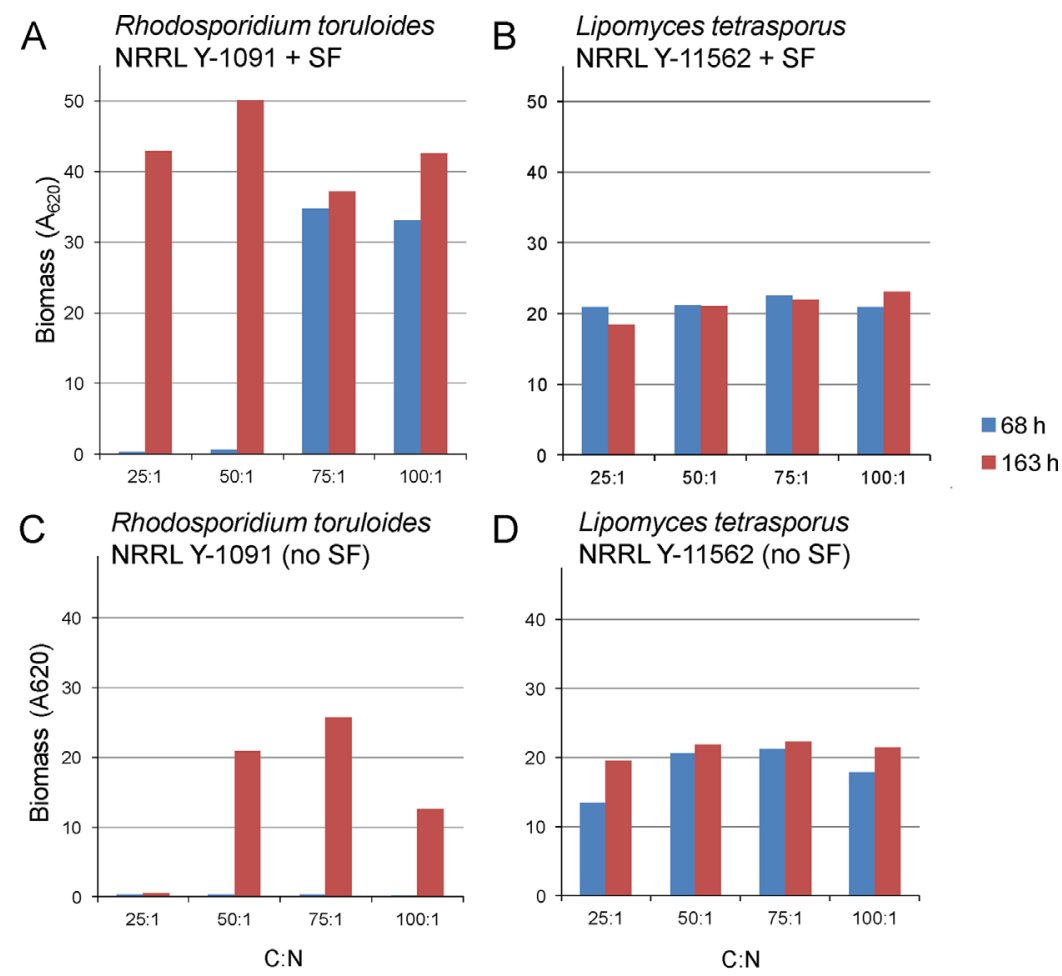

D Lipomyces tetrasporus
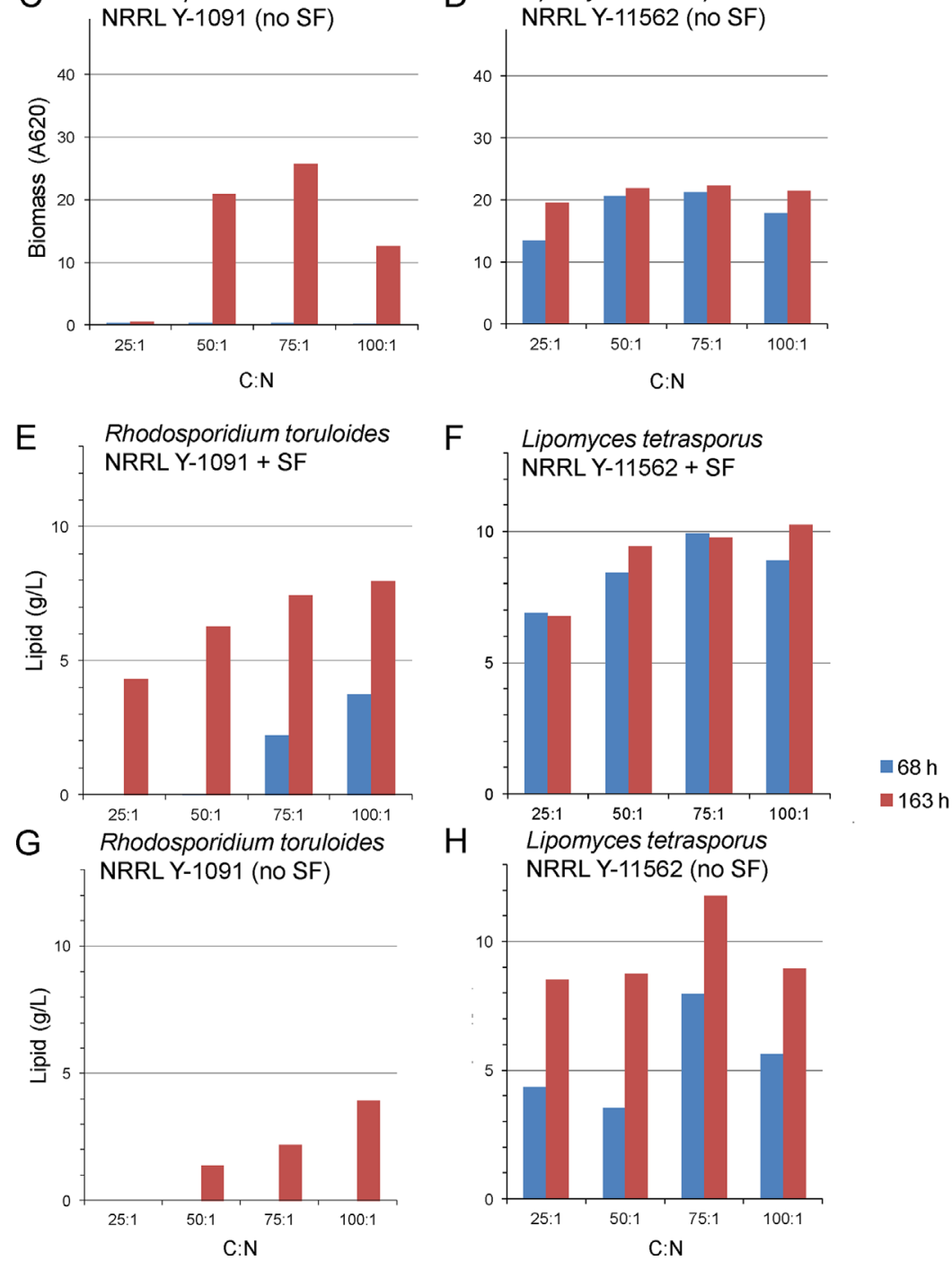

Figure 4. Significant impact of C:N and soy flour (SF) on growth (A-D) and lipid accumulation (E-H) by Rhodosporidium toruloides NRRL Y-1091 and Lipomyces tetrasporus NRRL Y-11562 cultivated in $75 \%$ strength SGH.

casamino acids, and potentially others. Additionally, consistent with the background literature (Jin et al., 2015), C:N ratios of 50-75 were required to support optimal cell growth and the initiation of abundant lipid accumulation. As summarized by previous reviews
(Sitepu et al., 2014; Weete, 1980) nutrients have been demonstrated to affect lipid accumulation: nitrogen, phosphorus, sulfur, amino acids, certain vitamins (thiamine, biotin, pyridoxine, pantothenate), and inositol are involved in fatty acid synthesis or 
desaturation reactions. For example, the biosynthesis of Coenzyme A $(\mathrm{CoA})$ required for FA biosynthesis relies on availability of cysteine, pantothenate and ATP. Additionally, Rodriguez-Frometa et al. (2013) studies have indicated the need for a fully functioning leucine biosynthetic pathway in order to support lipid accumulation through leucine degradation for acetyl-CoA generation to feed fatty acid biosynthesis. Thus, an avoidance of exogenously supplied leucine may be preferred to encourage endogenous leucine biosynthesis in this case. These two examples point out the potential sensitivity of the lipid productivity to amino acid availability that can be variable pending the protein source and method of hydrolysis to free amino acids (Cavins et al., 1972); cystein recovery is highly dependent on the hydrolysis process and tryptophan is known to be destroyed by acid hydrolysis.

In hydrolyzates which may challenge cell integrity, it is also conceivable that nutrient requirements may become accentuated to accommodate repair as suggested by the data presented here, which showed that the benefit of amino acid supplements increased as the strength of hydrolyzate was increased. The supplementation of soy flour to boost PAN was notably more important for $R$. toruloides NRRL Y-1091 than for L. tetrasporus NRRL Y-11562 and more important in $100 \%$ hydrolyzates than more dilute hydrolyzates. In future studies of each yeast strain, the supplementation of commercial nitrogen sources, which carry amino acids and potentially other nutrients noted above, would need to be optimized for performance and cost (Zabriski et al., 1980).

Building on these findings, the impacts of variations in key growth stage conditions-initial pH (6 or 7), SGH strength (50 or $75 \%$ ), and soy flour amino acid content (present or absent) —on the subsequent success of lipid amplification in the second stage cultivation were further explored in strain L. tetrasporus Y-11562. Results (not depicted) confirmed our earlier finding that first stage growth on $75 \%$ SGH compared to $50 \%$ SGH allowed significantly more abundant growth ( $\mathrm{A}_{620 \text {, } \max }$ of 61.7 vs. 43.7 , respectively) and lipid accumulation (16.1 vs. $11.7 \mathrm{~g} / \mathrm{L}$, respectively) in the first stage culture. In addition, results indicated that the use of 75\% SGH compared with 50\% SGH in first stage growth supported more abundant lipid accumulation in the second stage cultures $(33.6 \mathrm{~g} / \mathrm{L}$ vs. $30.9 \mathrm{~g} / \mathrm{L}$, respectively), which were resuspended in $100 \% \mathrm{SGH}$ at C:N greater than 500:1. However, neither the addition of soy flour nor the variation of $\mathrm{pH}$ between 6 and 7 in the growth stage had significant impact on cell accumulation in the first growth stage or lipid amplification in the second stage, indicating the robustness of the strain for growth and lipid production in this manner. Conducting the second stage lipid amplification at $\mathrm{pH} 6$ compared with $\mathrm{pH} 7$ resulted in similar performances, further indicating resilience to operation under acidic conditions. Operating at an acidic $\mathrm{pH}$ and a reduced nitrogen loading should discourage microbial contaminants.

Table $\mathrm{V}$ shows comparative performances under generally optimal conditions for all three of the more hydrolyzate-resilient yeast strains in the two-stage cultivation process scaled to $100 \mathrm{~mL}$ in baffled flasks. Aerobic conditions support abundant cell growth in the first stage culture (C:N $~ 62: 1)$ and carbon flow through the tricarboxylic acid cycle which also supplies citric acid and ATP for triacylglycerol biosynthesis in the second lipid amplification stage culture conducted at very high C:N $~ 600: 1$ in the SGH without nitrogen supplementation. Under these conditions, the low $\mathrm{N}$

Table V. Comparative lipid production kinetics of oleaginous yeast strains tested in two stage flask cultures to amplify lipid accumulation on SGH. The two stage process involved carrying out cell growth on 75\% strength SGH at C:N 62:1and pH 7 in stage 1 followed by resuspension of cells in 100\% strength SGH at C:N $200: 1$ and $\mathrm{pH} 7$ for amplified lipid accumulation in stage 2. $^{\mathrm{a}} \mathrm{b}$

\begin{tabular}{|c|c|c|c|c|c|c|c|c|c|}
\hline \multirow[b]{2}{*}{ Species } & \multirow[b]{2}{*}{$\begin{array}{l}\text { Strain } \\
\text { (NRRL) }\end{array}$} & \multirow[b]{2}{*}{$\begin{array}{l}\text { Culture } \\
\text { stage }\end{array}$} & \multicolumn{2}{|c|}{ Maximum biomass } & \multicolumn{5}{|c|}{ Maximum lipid } \\
\hline & & & $\begin{array}{c}\text { Absorbance } \\
\left(\mathrm{A}_{620}\right)\end{array}$ & $\begin{array}{c}\text { Dry weight } \\
(\mathrm{g} / \mathrm{L})\end{array}$ & $\begin{array}{c}\text { Concentration } \\
(\mathrm{g} / \mathrm{L})\end{array}$ & $\begin{array}{l}\text { Productivity } \\
\text { (g/L/h) }\end{array}$ & $\begin{array}{c}\text { Yield } \\
\text { (initial sugar) }(\mathrm{g} / \mathrm{g})\end{array}$ & $\begin{array}{c}\text { Yield } \\
\text { (sugar used) (g/g) }\end{array}$ & $\begin{array}{l}\text { Cell content } \\
\text { (g/g cells) }\end{array}$ \\
\hline $\begin{array}{l}\text { Lipomyces } \\
\quad \text { tetrasporus }\end{array}$ & Y-11562 & $\begin{array}{c}1 \\
2 \\
\text { Overall }\end{array}$ & $\begin{array}{l}50.9 \pm 0.8 \\
74.6 \pm 2.6\end{array}$ & $\begin{array}{c}- \\
54.3 \pm 2.0\end{array}$ & $\begin{array}{l}12.9 \pm 0.4 \\
29.0 \pm 1.0\end{array}$ & $\begin{array}{l}0.149 \pm 0.004 \\
0.337 \pm 0.007 \\
0.215 \pm 0.003\end{array}$ & $\begin{array}{l}0.143 \pm 0.004 \\
0.142 \pm 0.003 \\
0.142 \pm 0.002\end{array}$ & $\begin{array}{l}0.164 \pm 0.006 \\
0.150 \pm 0.003 \\
0.156 \pm 0.004\end{array}$ & $\begin{array}{c}- \\
0.53 \pm 0.03\end{array}$ \\
\hline $\begin{array}{l}\text { Lipomyces } \\
\quad \text { kononenkoae }\end{array}$ & Y-7042 & $\begin{array}{c}1 \\
2 \\
\text { Overall }\end{array}$ & $\begin{array}{l}46.2 \pm 2.3 \\
68.1 \pm 3.8\end{array}$ & $\begin{array}{c}- \\
47.7 \pm 0.6\end{array}$ & $\begin{array}{c}7.9 \pm 0.6 \\
28.1 \pm 1.4\end{array}$ & $\begin{array}{l}0.068 \pm 0.005 \\
0.470 \pm 0.032 \\
0.179 \pm 0.011\end{array}$ & $\begin{array}{l}0.087 \pm 0.007 \\
0.194 \pm 0.014 \\
0.146 \pm 0.010\end{array}$ & $\begin{array}{l}0.096 \pm 0.008 \\
0.217 \pm 0.016 \\
0.161 \pm 0.012\end{array}$ & $\begin{array}{c}- \\
0.59 \pm 0.04\end{array}$ \\
\hline $\begin{array}{c}\text { Rhodosporidium } \\
\text { toruloides }\end{array}$ & Y-1091 & $\begin{array}{c}1 \\
2 \\
\text { Overall }\end{array}$ & $\begin{aligned} 53.8 & \pm 2.4 \\
102.4 & \pm 1.4\end{aligned}$ & $\begin{array}{c}- \\
42.6 \pm 1.1\end{array}$ & $\begin{array}{l}10.3 \pm 0.2 \\
26.2 \pm 1.4\end{array}$ & $\begin{array}{l}0.073 \pm 0.001 \\
0.235 \pm 0.010 \\
0.128 \pm 0.003\end{array}$ & $\begin{array}{l}0.113 \pm 0.003 \\
0.147 \pm 0.007 \\
0.132 \pm 0.003\end{array}$ & $\begin{array}{l}0.127 \pm 0.004 \\
0.187 \pm 0.010 \\
0.159 \pm 0.004\end{array}$ & $\begin{array}{c}- \\
0.61 \pm 0.04\end{array}$ \\
\hline
\end{tabular}

\footnotetext{
${ }^{a}$ Means and standard deviations are tabulated based on data from flask cultures repeated in triplicate. Kinetic parameters are calculated based on culture time courses shown in Figure 5.

${ }^{\mathrm{b}}$ For culture stage 1 (yeast growth), maximum parameter values are those corresponding to the time of cell harvest for resuspension in culture stage 2 . The stage 1 lipid productivity was calculated as the lipid concentration at harvest divided by the harvest time. The stage 1 lipid yield was calculated as the lipid concentration formed per either the sugar supplied to stage 1 or the sugar consumed during stage 1 at the time of harvest. For culture stage 2 (lipid amplification), maximum parameter values correspond to the occurrence of the maximum lipid concentration. Since stage 2 contains an initial lipid concentration, the stage 2 lipid productivity was calculated as the lipid concentration increase during stage 2 divided by the time spent in stage 2 at the point of peak lipid concentration. The stage 2 lipid yield was calculated as the lipid concentration formed during stage 2 per either the sugar supplied to stage 2 or the sugar consumed during stage 2 at the time of peak lipid concentration. Overall process productivity was calculated based on the lipid accumulation in stages 1 and 2 per the total time in stages 1 and 2 until maximum lipid was reached. The overall yields were calculated in two ways: as the total lipid accumulation in stages 1 and 2 per the total of the initial sugars supplied (glucose, xylose, and arabinose) at the beginning of stages 1 and 2 or as the total lipid accumulation in stages 1 and 2 per total of the sugars actually used (glucose, xylose, and arabinose). Note that acetate consumption contributed less than $4 \%$ additional carbon to that supplied by sugars and was not included in any of the yield calculations.
} 


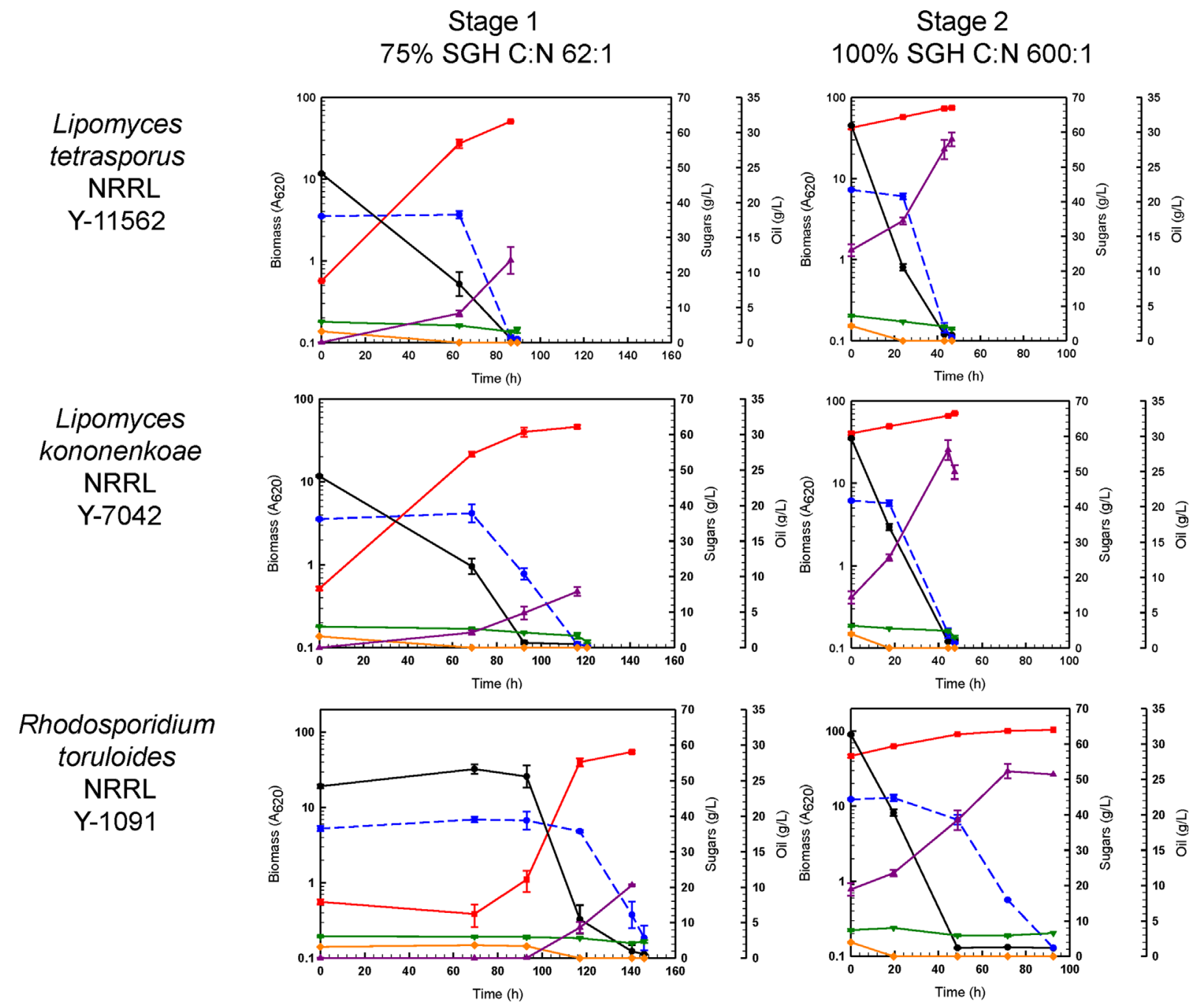

Figure 5. Flask culture time courses of three top yeast strains utilizing sugars to produce lipids in a two-stage process involving growth on $75 \%$ SGH at C:N $62: 1$ followed by resuspension of the cell population in 100\% SGH prepared with no N amendment for C:N 600:1: (A) Lipomyces tetrasporus NRRL Y-11562; (B) Lipomyces kononenkoae NRRL Y-7042; (C) Rhodosporidium toruloides NRRL Y-1091. Red squares represent biomass $\left(A_{620}\right)$, black circles with solid line are glucose, blue circles with dashed line are xylose, inverted green triangles are arabinose, and purple triangles are lipid. Error bars represent the standard deviation about the mean of three replicate flask culture results, designated by the respective symbols.

availability results in the diversion of citric acid flow toward lipid biosynthesis. (Ageitos et al., 2011; Beopoulos et al., 2011; Jin et al., 2015; Liang and Jiang, 2013; Ratledge and Wynn, 2002; Ratledge, 2004). For each of the three strains, the two stage processing led to much higher lipid accumulations (reaching 25-30 g/L), than ever previously reported for either detoxified or undetoxified hydrolyzates of lignocellulosic biomass of any kind (Jin et al., 2015). In the second lipid amplification stage, lipid productivities reached $0.24-0.47 \mathrm{~g} / \mathrm{L} / \mathrm{h}$ and were 3 to 7 times higher than those found in the first stage growth at the lower C:N level. Additionally, lipid yields per sugar consumed went from $0.09-0.16$ in the first stage to $0.15-0.22 \mathrm{~g} / \mathrm{g}$ in the second stage, nearing the $0.22 \mathrm{~g} / \mathrm{g}$ maximum practical yield typical of synthetic medium cultures (Jin et al., 2015). For all three strains, overall lipid yield of the two-stage process based on sugar consumed was essentially the same at $0.16 \mathrm{~g} / \mathrm{g}$, but in terms of lipid produced per sugar supplied, the overall yield was somewhat lower at $0.13-0.15 \mathrm{~g} / \mathrm{g}$ since there was some residual pentose at the end of first stage growth and/or at the time of maximum lipid in second stage lipid amplification (Fig. 5).

The lipid contents of cells at peak lipid accumulation were found to be in the range of $53-61 \%$ by weight (Table V). The fatty acid profiles of the lipid accumulated by each strain under these conditions are further described in Table SI. The accumulated lipid has composition that is compatible with the production of biodiesel fuel (Jin et al., 2015; Wahlen et al., 2013). Especially pertinent to optimizing degree of unsaturation and biodiesel fuel qualities, the oleic acid (18:1) content of fatty acids from lipid produced by our oleaginous yeasts is significantly higher than that found in most vegetable oils noted in the literature (see Dauqan et al., 2011; Dornbos and Mullen, 1992; Wood and Lee, 1983).

Coproduction of carotenoids was observed to occur with lipid accumulation by all three strains (Table SII). The known carotenoid 
producing strain, $R$. toruloides NRRL Y-1091, accumulated relatively abundant carotenoids per gram extracted lipid on SGH, including $0.75 \pm 0.07 \mu \mathrm{g}$ astaxanthin, $1.2 \pm 0.3 \mu \mathrm{g}$ canthaxanthin, $5.9 \pm 2.9 \mu \mathrm{g}$ echinenone, $4.3 \pm 0.5 \mu \mathrm{g}$ beta-carotene, $8.6 \pm 6.7 \mu \mathrm{g}$ lycopene, and $8.4 \pm 3.0 \mu \mathrm{g}$ gamma-carotene. Interestingly, low levels of 1-2 $\mu$ g echinenone, $2-4 \mu \mathrm{g}$ lycopene, and 1-3 $\mu$ g gammacarotene were also recovered per $\mathrm{g}$ of lipid produced by L. tetrasporus strain NRRL Y-11562 and its relative L. kononenkoae NRRL Y-7042, although relatively high standard deviations among replicates was noted, especially for gamma-carotene. Further studies are planned to characterize carotenoid production by these yeasts on hydrolyzates - since high value co-products are expected to favorably impact the economics of producing biodiesel from lignocellulose (Ratledge, 2011; Koutinas et al., 2014).

Each kinetic and yield property of the top strains in the two-stage process on undetoxified hydrolyzate (Table V) compared favorably to or better than previously reported for strains performing on detoxified hydrolyzates. This is significant because conditioning hydrolyzates is expected to be expensive and to affect downstream operations. The strains and process now reported as a result of this research allow superior kinetics on undetoxified hydrolyzates, even at the acidic $\mathrm{pH}$ of 6 (as demonstrated for Lipomyces sp. strains). For further comparison with the kinetics of the strains reported in Table V, the highest lipid accumulation previously reported on a hydrolyzate of lignocellulose was $15.8 \mathrm{~g} / \mathrm{L}$ for Trichosporon fermentans on a detoxified stream of dilute acid pretreated sugarcane bagasse at a productivity of $0.073 \mathrm{~g} / \mathrm{L} / \mathrm{h}$, and yield of $0.14 \mathrm{~g} / \mathrm{g}$ sugar consumed (Huang et al., 2012c). The highest lipid productivity reported was $0.21 \mathrm{~g} / \mathrm{L} / \mathrm{h}$ for Rhodotorula graminis on dilute acid pretreated corn stover enzyme hydrolyzate with lipid accumulation to $14.4 \mathrm{~g} / \mathrm{L}$ at a yield of $0.08 \mathrm{~g} / \mathrm{g}$ sugar consumed and cell content of 34\% lipid (Galafassi et al., 2012). The highest lipid yield reported was $0.23 \mathrm{~g} / \mathrm{g}$ sugar consumed during Cryptococcus curvatus bioconversion of ionic liquid pretreated corn stover, accumulating $7.2 \mathrm{~g} / \mathrm{L}$ lipid at a rate of $0.15 \mathrm{~g} / \mathrm{L} / \mathrm{h}$, achieving a cell content of 43.4\% lipid (Gong et al., 2013). The high lipid content of $58.5 \%$ was reported for Yarrowia lipolytica Po $1 \mathrm{~g}$ on detoxified acid hydrolyzate of sugarcane bagasse, where $6.7 \mathrm{~g} / \mathrm{L}$ lipid was accumulated at $0.07 \mathrm{~g} / \mathrm{L} / \mathrm{h}$ at a yield near theoretical at $0.33 \mathrm{~g} / \mathrm{g}$ sugar consumed (Tsigie et al., 2011). A more complete table of the lipid kinetics for yeasts using detoxified hydrolyzates has been recently summarized (Jin et al., 2015).

\section{Conclusions}

Both AFEX CSH and SGH were useful substrates for determining aptitude of potential oleaginous yeast strains for high lipid accumulation and productivity on hydrolyzate. The SGH was more selective for robustness in hydrolyzates than the AFEX CSH, especially with respect to growth. About $25 \%$ of the oleaginous strains performed well on AFEX CSH whereas only about $10 \%$ of the strains performed on SGH. Of the $10 \%$ of strains that performed well on SGH, three strains demonstrated very high lipid accumulations, productivities, and yields in a two stage process involving cell production and initial lipid production in stage 1 hydrolyzate with $\mathrm{C}: \mathrm{N} \sim 50-75: 1$ followed by lipid amplification in stage 2 on much higher C:N $\sim 400-500: 1$. Using this process three strains were able to use acetic acid and nearly all of the available sugar, including xylose and arabinose. The achieved lipid accumulations of $25-30 \mathrm{~g} / \mathrm{L}$ at rates of $0.12-0.22 \mathrm{~g} / \mathrm{L} / \mathrm{h}$ and $0.13-0.15 \mathrm{~g} / \mathrm{g}$ or $39-45 \%$ of the theoretical yield at $\mathrm{pH} 6$ and 7 are unprecedented on lignocellulosic hydrolyzates of any kind. It is notable that the hydrolyzates used in this study were undetoxified. Strains demonstrating superior performance in our screens and two-stage process included Lipomyces tetrasporus NRRL Y-11562, Lipomyces kononenkoae NRRL Y-7042, and Rhodosporidium toruloides NRRL Y-1091, the latter being notable for its carotenoid production. Superior strains performing well in our AFEX CSH and SGH single stage batch cultivation also included the unique yeast Saitoella coloradoensis NRRL Y-2330, which was also able to produce carotenoid co-products in addition to lipids, a characteristic which may be of key importance to economic feasibility of the lignocellulose to biodiesel bioconversion process. This is the first report of strains of Lypomyces tetrasporus, Lypomyces kononenkoae, and Saitoella coloradoensis species as having superior ability to convert hydrolyzates of lignocellulose to lipids for the production of high quality biodiesel fuels.

The authors would like to recognize with sincere gratitude Drs. Kenneth P. Vogel, Gautam Sarath, and Robert B. Mitchell of the Grain, Forage, and Bioenergy Research Unit, Agricultural Research Service, U.S. Department of Agriculture, Lincoln, Nebraska for switchgrass used in this study. We would also like to thank Benetria Banks and Maureen Shea-Andersh for their valuable technical assistance to support the project.

\section{References}

Ageitos JM, Vallejo JA, Veiga-Crespo P, Villa TG. 2011. Oily yeasts as oleaginous cell factories. Appl Microbiol Biotechnol 90(4):1219-1227.

Balan V, Bals B, Chundawat S, Marshall D, Dale BE. 2009. Lignocellulosic biomass pretreatment using AFEX. In: Mielenz JR, editor. Biofuels: Methods and protocols, methods in molecular biology. New York: Humana Press, a part of Springer Science+Business Media, LLC. p 61-77.

Bates G, Keyser P, Harper C, Waller J. 2008. Using switchgrass for forage (https:// utextension.tennessee.edu/publications/documents/SP701-B.pdf). UTBiofuelsInitiative University of Tennessee Institute of Agriculture. 2008.

Beopoulos A, Nicaud JM, Gaillardin C. 2011. An overview of lipid metabolism in yeasts and its impact on biotechnological processes. Appl Environ Microbiol 90(4):1193-1206.

Bothast RJ, Saha BC. 1997. Ethanol production from agricultural biomass substrates. Adv Appl Microbiol 44:261-286.

Casey E, Sedlak M, Ho NWY, Mosier NS. 2010. Effect of acetic acid and pH on the cofermentation of glucose and xylose to ethanol by a genetically engineered strain of Saccharomyces cerevisiae. FEMS Yeast Res 10:385-393.

Cavins JF, Kwolek WF, Inglett GE, Cowan JC. 1972. Amino acid analysis of soybean meal: Interlaboratory study. J Assoc Off Anal Chem 55(4):686-691.

Dauqan EMA, Sani HA, Abdullah A, Kasim ZM. 2011. Fatty acids composition of four different vegetable oils (red palm olein, palm olein, corn oil and coconut oil) by gas chromatography 2nd international conference on chemistry and chemical engineering. Singapore: IACSIT Press.

Dien BS, Jung H-J, Vogel K, Casler M, Lamb J, Iten L, Mitchell R, Sarath G. 2006. Chemical composition and response to dilute-acid pretreatment and enzymatic saccharification of alfalfa, reed canarygrass, and switchgrass. Biomass Bioenergy 30(10):880-891.

Dien BS, O'Bryan P, Hector R, Iten L, Mitchell R, Qureshi N, Sarath G, Vogel K, Cotta M. 2013. Conversion of switchgrass to ethanol using dilute ammonium hydroxide pretreatment: Influence of ecotype and harvest maturity. Environ Technol 34(13-14):1837-1848.

Dien BS, Slininger PJ, Kurtzman CP, Moser BR, O’Bryan PJ. 2016. Identification of superior lipid producing Lipomyces and Myxozyma yeasts. AIMS Environ Sci 3(1):1-20. 
Dornbos DL, Jr., Mullen RE. 1992. Soybean seed protein and oil contents and fatty acid composition adjustments by drought and temperature. J Am Oil Chem Soc 69(3):228-231.

Dugar D, Stephanopoulos G. 2011. Relative potential of biosynthetic pathways for biofuels and bio-based products. Nat Biotechnol 29(12):1074-1078.

Galafassi Sea. 2012. Lipid production for second generation biodiesel by the oleaginous yeast Rhodotorula graminis. Bioresour Technol 111:398-403.

Gao C, Xiong W, Zhang Y, Yuan W, Wu Q. 2008. Rapid quantitation of lipid in microalgae by time-domain nuclear magnetic resonance. J Microbiol Methods 75(3):437-440.

Gong ZW. 2013. Efficient conversion of biomass into lipids by using simultaneous saccharification and enhanced lipid production process. Biotechnol Biofuels $6: 36$.

Hahn-Hägerdal B, Karhuman K, Fonseca C, Spencer-Martins I, Gorwa-Grauslund MF. 2007. Towards industrial pentose-fermenting yeast strains. Appl Microbiol Biotechnol 74:937-953.

Hart DJ, Scott KJ. 1995. Development and evaluation of an HPLC method for the analysis of carotenoids in foods, and the measurement of the carotenoid content of vegetables and fruits commonly consumed in the UK. Food Chem 54(1):101-111.

Heredia L, Ratledge C. 1988. Simultaneous utilization of glucose and xylose by Candida curvata D in continuous culture. Biotechnol Lett 10:25-30.

$\mathrm{Hu}$ CM, Wu S, Wang Q, Jin G, Shen H, Zhao ZK. 2011. Simultaneous utilization of glucose and xylose for lipid production by Trichosporon cutaneum. Biotechnol Biofuels 4:25.

Huang C, Chen X-f, Xiong L, Chen X-d, Ma L-1. 2012a. Oil production by the yeast Trichosporon dermatis cultured in enzymatic hydrolysates of corncobs. Bioresour Technol 110:711-714.

Huang C, Hong W, Liu Z-j, Cai J, Lou W-y, Zong M-h. 2012b. Effect of organic acids on the growth and lipid accumulation of oleaginous yeast Trichosporon fermentans. Biotechnol Biofuels 5:4.

Huang C, Wu H, Li R-f, Zong M-h. 2012c. Improving lipid production from bagasse hydrolysate with Trichosporon fermentans by response surface methodology. N Biotechnol 29:372-378.

Ichihara K, Shibahara A, Yamamoto K, Nakayama T. 1996. An improved method for rapid analysis of the fatty acids of glycerolipids. Lipids 31:535-539.

Izard J, Limberger RJ. 2003. Rapid screening method for quantitation of bacterial cell lipids from whole cells. J Microbiol Methods 55(2):411-418.

Jeffries TW, Jin Y-S. 2004. Metabolic engineering for improved fermentation of pentoses by yeasts. Appl Environ Microbiol 63:495-509.

Jin M, Gunawan C, Uppugundla N, Balan V, Dale BE. 2012. A novel integrated biological process for cellulosic ethanol production featuring high ethanol productivity, enzyme recycling, and yeast cells reuse. Energy Environ Sci 5:7168-7175.

Jin M, Slininger PJ, Dien BS, Waghmode SB, Moser BR, Sousa LdC, Orjuela A, Balan V. 2015. Microbial lipid based lignocellulosic biorefinery: Feasibility and challenges. Trends Biotechnol 33(1):43-54.

Koutinas A, Chatzifragkou A, Kopsahelis N, Papanikolaou S, Kookos I. 2014. Design and techno-economic evaluation of microbial oil production as a renewable resource for biodiesel and oleochemical production. Fuel 116:566-577.

Kurtzman CP, Fell JW, Boekhout T. 2011. The yeasts: A taxonomic study. Amsterdam: Elsevier Science. p 2354.

Kurtzman CP, Robnett CJ. 2012. Saitoella coloradoensis sp. nov., a new species of the Ascomycota, subphylum Taphrinomycotina. Antonie Van Leeuwenhoek 101(4):795-802.

Lee YY, Iyer P, Torget RW. 1999. Dilute-acid hydrolysis of lignocellulosic biomass. Adv Biochem Eng Biotechnol 65:93-115.

Li Q, Du W, Liu D. 2008. Perspectives of microbial oils for biodiesel production. Appl Microbiol Biotechnol 80(5):749-756.

Liang M-H, Jiang J-G. 2013. Advancing oleaginous microorganisms to produce lipid via metabolic engineering technology. Prog Lipid Res 52(4):395-408.

Moreton R. 1989. Yeast lipid estimation by enzymatic and nuclear magnetic resonance methods. Appl Microbiol Biotechnol 55(11):3009-3011.

Palmqvist E, Hahn-Hägerdal B. 2000a. Fermentation of lignocellulosic hydrolysates. I: Inhibition and detoxification. Bioresour Technol 74(1):17-24.

Palmqvist E, Hahn-Hägerdal B. 2000b. Fermentation of lignocellulosic hydrolysates. II: Inhibitors and mechanisms of inhibition. Bioresour Technol 74(1):25-33.
Pan JG, Kwak MY, Rhee JS. 1986. High density cell culture of Rhodotorula glutinis using oxygen-enriched air. Biotechnol Lett 8(10):715-718.

Prior BA, Kilian SG, duPreez JC. 1989. Fermentation of D-xylose by the yeasts Candida shehatae and Pichia stipitis. Process Biochem 24(1):21-32.

Ratledge C. 2004. Fatty acid biosynthesis in microorganisms being used for single cell oil production. Biochimie 86(11):807-815.

Ratledge C. 2011. A portrait in microbial oils. Inform 22(7):440-441.

Ratledge C, Cohen Z. 2008. Microbial and algal oils: Do they have a future for biodiesel or as commodity oils? Lipid Technol 20(7):155-160.

Ratledge C, Wynn JP. 2002. The biochemistry and molecular biology of lipid accumulation in oleaginous microorganisms. Advances in applied microbiology. Cambridge MA: Academic Press. p 1-51.

Rodriguez-Amaya DB. 2001. A guide to carotenoid analysis in foods. Washington, DC: ILSI Press, International Life Sciences Institute. p 64.

Rodriguez-Frometa RA, Gutierrez A, Torres-Martinez S, Garre V. 2013. Malic enzyme activity is not the only bottleneck for lipid accumulation in the oleaginous fungus Mucor circinelloides. Appl Microbiol Biotechnol 97:3063-3072.

Sitepu IR, Sestric R, Ignatia L, Levin D, Bruce German J, Gillies LA, Almada LA, Boundy-Mills KL. 2013. Manipulation of culture conditions alters lipid content and fatty acid profiles of a wide variety of known and new oleaginous yeasts species. Bioresour Technol 144:360-369.

Sitepu I, Garay L, Sestric R, Levin D, Block DE, German J, Boundy-Mills K. 2014. Oleaginous yeasts for biodiesel: Current and future trends in biology and production. J Biotechnol Adv 32(7):1336-1360.

Slininger PJ, Bothast RJ, VanCauwenberge JE, Kurtzman CP. 1982. Conversion of Dxylose to ethanol by the yeast Pachysolen tannophilus. Biotechnol Bioeng 24:371-384

Slininger PJ, Shea-Andersh MA, Thompson SR, Dien BS, Kurtzman CP, Balan V, Sousa LdC, Uppugundla N, Dale BE, Cotta MA. 2015. Evolved strains of Scheffersomyces stipitis achieving high ethanol productivity on acid- and basepretreated biomass hydrolyzate at high solids loading. Biotechnol Biofuels 8:60.

Tsigie YA, Wang C-Y, Truong C-T, Ju Y-H. 2011. Lipid production from Yarrowia lipolytica Polg grown in sugarcane bagasse hydrolysate. Bioresour Technol 102(19):9216-9222.

U.S. Department of Energy. 2011. In: Perlack RD, Stokes BJ, editors. U.S. Billion-ton update: Biomass supply for a bioenergy and bioproducts industry. Oak Ridge, TN: ORNL/TM-2011/224. Oak Ridge National laboratory. p 227.

Wahlen BD, Morgan MR, McCurdy AT, Willis RM, Morgan MD, Dye DJ, Bugbee B, Wood BD, Seefeldt LC. 2013. Biodiesel from microalgae, yeast, bacteria: Engine performance and exhaust emissions. Energy Fuels 27:220-228.

Wang J, Li R, Lu D, Ma S, Yan Y, Li W. 2009. A quick isolation method for mutants with high lipid yield in oleaginous yeast. World J Microbiol Biotechnol 25(5):921-925.

Weete JD. 1980. Chapter 2 Fungal lipids. In: Weete JD, editor. Lipid biochemistry of fungi and other organisms. New York: Plenum Press. p 9-48.

Wood R, Lee T. 1983. High-performance liquid chromatography of fatty acids: Quantitative analysis of saturated, monoenoic, polyenoic and geometrical isomers. J Chromatogr 254:237-246.

Xie HB, Shen H, Gong Z, Wang Q, Zhao ZK, Bai F. 2012. Enzymatic hydrolysates of corn stover pretreated by a $\mathrm{N}$-methylpyrrolidone-ionic liquid solution for microbial lipid production. Green Chem 14:1202-1210.

Yu X, Zheng Y, Dorgan KM, Chen S. 2011. Oil production by oleaginous yeasts using the hydrolysate from pretreatment of wheat straw with dilute sulfuric acid. Bioresour Technol 102:6134-6140.

Zabriski DW, Armiger WB, Phillips DH, Albano PA. 1980. Fermentation media formulation. In: Trader's guide to fermentation media formulation. Memphis, Tennessee: Trader's Protein. p 1-39.

Zhao X, Kong X, Hua Y, Feng B, Zhao ZK. 2008. Medium optimization for lipid production through co-fermentation of glucose and xylose by the oleaginous yeast Lipomyces starkeyi. Eur J Lipid Sci Technol 110:405-412.

\section{Supporting Information}

Additional supporting information may be found in the online version of this article at the publisher's web-site. 